\title{
Blockage of androgen and administration of estrogen induce transdifferentiation of testis into ovary
}

\author{
Hongjuan Shi*, Tian Gao*, Zhilong Liu*, Lina Sun*, Xiaolong Jiang, Lili Chen \\ and Deshou Wang
}

Key Laboratory of Freshwater Fish Reproduction and Development (Ministry of Education), Key Laboratory of Aquatic Science of Chongqing, School of Life Sciences, Southwest University, Chongqing, People's Republic of China

*(H Shi, T Gao, Z Liu and L Sun contributed equally)

Correspondence should be addressed to D Wang

Email

wdeshou@swu.edu.cn

\begin{abstract}
Induction of sex reversal of $X Y$ fish has been restricted to the sex undifferentiated period. In the present study, differentiated $X Y$ tilapia were treated with trilostane (TR), metopirone (MN) and glycyrrhetinic acid (GA) (inhibitor of 3 $\beta-H S D$, Cyp $11 \mathrm{~b} 2$ and $11 \beta-$ HSD, respectively) alone or in combination with 17 $\beta$-estradiol (E2) from 30 to 90 dah (days after hatching). At 180 dah, E2 alone resulted in 8.3\%, and TR, MN and GA alone resulted in no secondary sex reversal (SSR), whereas TR +E2, MN +E2 and GA +E2 resulted in $88.3,60.0$ and $46.7 \%$ of SSR, respectively. This sex reversal could be rescued by simultaneous administration of 11-ketotestosterone (11-KT). Compared with the control XY fish, decreased serum 11-KT and increased E2 level were detected in SSR fish. Immunohistochemistry analyses revealed that Cyp19a1a, Cyp11b2 and Dmrt1 were expressed in the gonads of GA+E2, MN +E2 and TR+E2 SSR XY fish at 90 dah, but only Cyp19a1a was expressed at 180 dah. When the treatment was applied from 60 to 120 dah, $\mathrm{TR}+\mathrm{E} 2$ resulted in $3.3 \%$ of SSR, MN +E2 and GA+E2 resulted in no SSR. These results demonstrated that once 11-KT was synthesized, it could antagonize E2-induced male-tofemale SSR, which could be abolished by simultaneous treatment with the inhibitor of steroidogenic enzymes. The upper the enzyme was located in the steroidogenic pathway, the higher SSR rate was achieved when it was inhibited as some of the precursors, such as androstenedione, testosterone and $5 \alpha$-dihydrotestosterone, could act as androgens. These results highlight the key role of androgen in male sex maintenance.
\end{abstract}

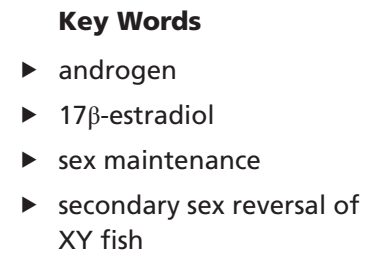

Journal of Endocrinology (2017) 233, 65-80

\section{Introduction}

In fish, sex is determined by both genetic and environmental factors. The latter, especially sex steroid hormones, could even override the genetic factors and change the fate of the gonad. In teleost, endogenous estrogens are synthesized in the ovary during the critical period of molecular sex differentiation and act as the natural inducer of ovarian differentiation (Nagahama 2000, Tao et al. 2013). In females, treatment with aromatase

Published by Bioscientifica Ltd. 
inhibitors (AI), before and during the period of molecular sex differentiation, induces primary sex reversal (PSR) of the undifferentiated ovary into testis (Piferrer et al. 1994, Guiguen et al. 1999, Kwon et al. 2000, Suzuki et al. 2004). Estrogens also play key roles in female sex maintenance. Long-term treatment with AI even induces secondary sex reversal (SSR) of the morphologically differentiated ovary into functional testis (Paul-Prasanth et al. 2013, Takatsu et al. 2013, Sun et al. 2014). In species with natural sex reversal (NSR), the serum 17ß-estradiol (E2) level decreases rapidly during female-to-male sex reversal in protogynous fishes (Nakamura et al. 1989, Kokokiris et al. 2006, Nozu \& Nakamura 2015), whereas it increases during male-to-female sex reversal in protandrous fishes (Chang \& Yueh 1990, Guiguen et al. 1993, Chang et al. 1994). In contrast, treatment with AI induces female-tomale sex reversal in protogynous fishes (Bhandari et al. $2004 a, b, 2005$, Benton \& Berlinsky 2006) and blocks maleto-female NSR in protandrous fish (Lee et al. 2001, 2002).

Many studies have demonstrated that male-to-female PSR could be induced, before and during molecular sex differentiation by the administration of exogenous estrogens in teleosts, including tilapia (Tayaman \& Shelton 1978, Guiguen et al. 1999, Gennotte et al. 2014), medaka (Yamamoto 1953, Kobayashi \& Iwamatsu 2005), pufferfish (Lee et al. 2009), trout (Guiguen et al. 1999, Vizziano et al. 2007, Vizziano-Cantonnet et al. 2008), fathead minnow (Watanabe et al. 2009), pejerrey (Strüssmann et al. 1996, Pérez et al. 2012), mahseer, common carp and catfish (Singh 2013). Nevertheless, once the gonad is morphologically differentiated, it is very difficult or even impossible to induce sex reversal of genetic male by administration of estrogens. During this period, an important fact is that the steroidogenic enzymes genes, such as cyp11a1 (cytochrome P450, family 11 , subfamily A, polypeptide 1), $3 \beta$-HSD (3$\beta$-hydroxysteroid dehydrogenase/isomerase), cyp17a (cytochrome P450, family 17 and subfamily A), especially cyp 11 b2 (cytochrome P450, family 11 , subfamily $\mathrm{B}$, polypeptide 2 ), the key enzyme for 11-ketotesterone (11-KT, the main androgen in most teleosts) synthesis, started to get expressed in Leydig cells of the testis, and consequently, the androgen level was significantly upregulated in teleost (Borg 1994, Kobayashi et al. 1998, Nakamura et al. 1998, Vizziano et al. 2007, Pérez et al. 2012). In tilapia, gonadal morphological differentiation occurs at approximately 23-26 dah (Nakamura \& Nagahama 1989). These enzymes Cyp11a1/cyp11a1, Cyp17a1/cyp17a1 and Cyp11b2/cyp11b2 have not been detected until approximately at 30 dah in the testis of the XY fish by immunohistochemistry (IHC) and transcriptome analyses (Kobayashi et al. 1996, Nagahama 2000, Bhandari et al. 2006, Ijiri et al. 2008, Tao et al. 2013). It is well accepted that endogenous androgens are critical for testicular morphological differentiation (Pérez et al. 2012) and spermatogenesis (Miura et al. 1991, Cavaco et al. 2001, Zhang et al. 2010). Therefore, it would be interesting to examine whether endogenous androgens in the morphologically differentiated testis antagonize exogenous estrogens-induced male-to-female SSR in XY fish.

The Nile tilapia (Oreochromis niloticus) is a good species for the study of sex differentiation. It is a gonochoristic fish with an XX/XY sex determination system. In this study, we treated XY tilapia with trilostane (TR), metopirone (MN) and glycyrrhetinic acid (GA) (inhibitor

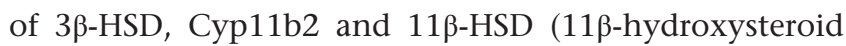
dehydrogenase), respectively) alone or in combination with E2 from 30 to 90 dah (Marandici \& Monder 1993, Villeneuve et al. 2008, Rigel et al. 2010). We analyzed the gonad phenotype, rate of sex reversal, gene expression profile and serum hormone levels. Our results indicated that androgens were critical for sex maintenance in males. This experimentally induced SSR of the morphologically differentiated testis into functional ovary was first described in tilapia, even in teleosts.

\section{Materials and methods}

\section{Animals}

Nile tilapia were reared in recirculating aerated freshwater tanks at $26^{\circ} \mathrm{C}$ under a natural photoperiod. All-XX progenies were obtained by crossing an $\mathrm{XX}$ pseudomale with a normal XX female. All-XY progenies were obtained by crossing an YY supermale with a normal female. Animal experiments were conducted in accordance with the regulations of the Guide for Care and Use of Laboratory Animals and were approved by the Committee of Laboratory Animal Experimentation at Southwest University.

\section{Hormone treatment}

Experiment 1: The 30 dah $\mathrm{XY}$ fish were divided into TR, $\mathrm{MN}, \mathrm{GA}, \mathrm{E} 2, \mathrm{TR}+\mathrm{E} 2, \mathrm{MN}+\mathrm{E} 2, \mathrm{GA}+\mathrm{E} 2, \mathrm{TR}+\mathrm{E} 2+11-\mathrm{KT}$, $\mathrm{MN}+\mathrm{E} 2+11-\mathrm{KT}, \quad \mathrm{GA}+\mathrm{E} 2+11-\mathrm{KT}, \quad \mathrm{TR}+\mathrm{E} 2+\mathrm{MT}$, $\mathrm{MN}+\mathrm{E} 2+\mathrm{MT}$ and $\mathrm{GA}+\mathrm{E} 2+\mathrm{MT}$ treatment groups. The $\mathrm{XY}$ fish were treated with commercial diet sprayed with 
95\% ethanol containing the same dose of TR, MN, GA (Sigma-Aldrich, $150 \mu \mathrm{g} / \mathrm{g}$ feed) alone or in combination with E2 (Sigma-Aldrich, $150 \mu \mathrm{g} / \mathrm{g}$ feed) and rescued by administration of 11-KT and MT (17 $\alpha$-methyltestosterone) (Sigma-Aldrich, $150 \mu \mathrm{g} / \mathrm{g}$ feed) from 30 to $90 \mathrm{dah}$, and then fed with normal commercial diet till 180 dah, when the fish were sampled. The control XX and XY fish were raised in steroid- and drug-free water and fed with normal commercial diet sprayed with $95 \%$ ethanol.

Experiment 2: The 60 dah XY fish were divided into $\mathrm{E} 2, \mathrm{TR}+\mathrm{E} 2, \mathrm{MN}+\mathrm{E} 2$ and $\mathrm{GA}+\mathrm{E} 2$ treatment groups. The $\mathrm{XY}$ fish were treated with commercial diet sprayed with $95 \%$ ethanol containing $150 \mu \mathrm{g} / \mathrm{g}$ feed of E2 alone or in combination with TR, MN and GA $(150 \mu \mathrm{g} / \mathrm{g}$ feed) from 60 to $120 \mathrm{dah}$, and then fed with normal commercial diet till 180 dah. The control $\mathrm{XX}$ and $\mathrm{XY}$ fish were raised as described in experiment 1.

The gonads were sampled at 60, 90, 120, 150 and 180 dah and fixed in Bouin's solution for subsequent histological observations. The gonads from the control $\mathrm{XX}$, control $\mathrm{XY}, \mathrm{TR}, \mathrm{MN}, \mathrm{GA}, \mathrm{E} 2, \mathrm{TR}+\mathrm{E} 2+11-\mathrm{KT}$, $\mathrm{MN}+\mathrm{E} 2+11-\mathrm{KT}, \quad \mathrm{GA}+\mathrm{E} 2+11-\mathrm{KT}$ and sex-reversed $\mathrm{TR}+\mathrm{E} 2, \mathrm{MN}+\mathrm{E} 2$ and $\mathrm{GA}+\mathrm{E} 2$ treatment $\mathrm{XY}$ fish were sampled for IHC analysis and serum for enzyme immunoassay (EIA) at 90, 120, 150 and 180 dah, and for real-time PCR at 90 and $180 \mathrm{dah}$. The gonad phenotype and sex reversal rate were determined by histological examination at 180 dah.

Experiment 3: The $\mathrm{XX}$ fish were divided into A4 (androstenedione), $\mathrm{T}$ (testosterone) and DHT (dihydrotestosterone) experiment groups. The newly hatched XX fry were firstly exposed to A4 (Xiya Reagent, Chengdu, China), testosterone (Sigma-Aldrich) and DHT (Sigma-Aldrich) $50 \mu \mathrm{g} / \mathrm{L}$ water from 0 to $5 \mathrm{dah}$, and then fed with commercial diet sprayed with $95 \%$ ethanol containing A4, testosterone and DHT $(50 \mu \mathrm{g} / \mathrm{g}$ diet $)$ until $30 \mathrm{dah}$. The control $\mathrm{XX}$ and $\mathrm{XY}$ fish were raised as described previously.

The gonads of the control XX, control XY, A4, testosterone and DHT treatment XX fish were sampled at 30 dah and fixed in Bouin's solution for subsequent histological observations and IHC analysis. The gonad phenotype and sex reversal rate were determined by histological examination and IHC analyses at 30 dah.

\section{IHC analyses}

IHC analyses were performed as described previously (Sun et al. 2014, Xie et al. 2016). Photographs were taken under an Olympus BX51 light microscope (Olympus).

\section{Measurement of serum 11-KT and E2 levels by EIA}

Blood samples were collected from the caudal veins of the control XX, XY and treatment XY fish at 90 and 150 dah, and then, kept at $4^{\circ} \mathrm{C}$ overnight. Serums were collected after centrifugation and stored at $-20^{\circ} \mathrm{C}$ until use. Serum 11-KT and E2 levels were measured using EIA Kit (Cayman) according to the manufacturer's instructions.

\section{Real-time PCR analysis}

Gonads were dissected from the control XX, XY and treatment $\mathrm{XY}$ fish at 90 dah. Total RNA extraction, reverse transcription and real-time PCR were performed as described previously (Chen et al. 2016). The relative abundances of foxl2 (forkhead box 12), cyp19a1a (cytochrome P450, family 19, subfamily A, polypeptide 1a), sf1 (steroidogenic factor 1), dmrt1 (doublesex and mab-3-related transcription factor 1), gsdf (gonadal somaderived factor), cyp11b2, cyp26a1 (cytochrome P450, family 26 , subfamily A) and scp3 (synaptonemal complex protein-3) mRNA transcripts were evaluated using the formula: $R=2^{-\Delta \Delta \mathrm{Ct}}$, as described previously (Tao et al. 2013, Sun et al. 2014). The expression values were normalized as described in our previous study (Chen et al. 2016). Primer sequences used for real-time PCR are listed in Supplementary Table 1 (see section on supplementary data given at the end of this article).

\section{Results}

\section{SSR was successfully induced by treatment of XY fish from 30 to 90 dah}

The gonad phenotypes of all experimental fish were examined histologically at 180 dah. All control XY fish developed as male with normal testis and all control XX fish developed as female with normal ovary. Treatment of 30 dah XY fish with TR, MN and GA alone for 60 days resulted in no male-to-female SSR, whereas with E2 alone resulted in $8.3 \%$ SSR. Interestingly, $\mathrm{TR}+\mathrm{E} 2, \mathrm{MN}+\mathrm{E} 2$ and GA+E2 treatment produced 88.3, 60.0 and $46.7 \%$ SSR in XY fish, respectively. The SSR was rescued by simultaneous administration of 11-KT or MT (Table 1 and Supplementary Table 2).

Histologically, in control XY gonad, spermatogonia were observed at 60 dah, primary and secondary spermatocytes appeared at 90 dah, spermatids appeared at 120 dah and spermatozoa appeared 180 dah (Fig. 1A, B, C and D). The 11-KT rescued XY fish displayed similar testis development

Published by Bioscientifica Ltd. 
Table 1 Gonadal phenotype and SSR rate at 180 dah.

\begin{tabular}{|c|c|c|c|c|c|}
\hline Treatment & Fish examined & Testis & Ovotestis & Ovary & Sex reversal rate $(\%)$ \\
\hline Control XX & 60 & 0 & 0 & 60 & 0 \\
\hline Control XY & 60 & 60 & 0 & 0 & 0 \\
\hline TR & 60 & 60 & 0 & 0 & 0 \\
\hline MN & 60 & 60 & 0 & 0 & 0 \\
\hline GA & 60 & 60 & 0 & 0 & 0 \\
\hline E2 & 60 & 55 & 5 & 0 & 8.3 \\
\hline $\mathrm{TR}+\mathrm{E} 2$ & 60 & 7 & 14 & 39 & 88.3 \\
\hline $\mathrm{MN}+\mathrm{E} 2$ & 60 & 24 & 18 & 18 & 60.0 \\
\hline $\mathrm{GA}+\mathrm{E} 2$ & 60 & 32 & 10 & 18 & 46.7 \\
\hline $\mathrm{TR}+\mathrm{E} 2+11-\mathrm{KT}$ & 60 & 60 & 0 & 0 & 0 \\
\hline $\mathrm{MN}+\mathrm{E} 2+11-\mathrm{KT}$ & 60 & 60 & 0 & 0 & 0 \\
\hline $\mathrm{GA}+\mathrm{E} 2+11-\mathrm{KT}$ & 60 & 60 & 0 & 0 & 0 \\
\hline
\end{tabular}

In the experiment 1, the $\mathrm{XY}$ fish were treated with TR, MN and GA alone or in combination with $\mathrm{E} 2$ at a concentration of $150 \mu \mathrm{g} / \mathrm{g}$ diet from 30 to 90 dah. 11-KT was used to rescue sex reversal induced by TR+E2, MN +E2 and GA+E2 treatment. The phenotype of fish was determined by gonad histology at 180 dah.

to the control XY fish. Compared with the control XY gonad, delayed spermatogenesis was observed in the TR, MN and GA $\mathrm{XY}$ gonad, with only spermatogonia observed at 60 and 90 dah, primary spermatocytes appeared at 120 dah, secondary spermatocytes and spermatids appeared at 180 dah (Fig. 1E, $\mathrm{F}, \mathrm{G}$ and $\mathrm{H})$. In the TR+E2, MN+E2 and GA+E2 SSR gonad,

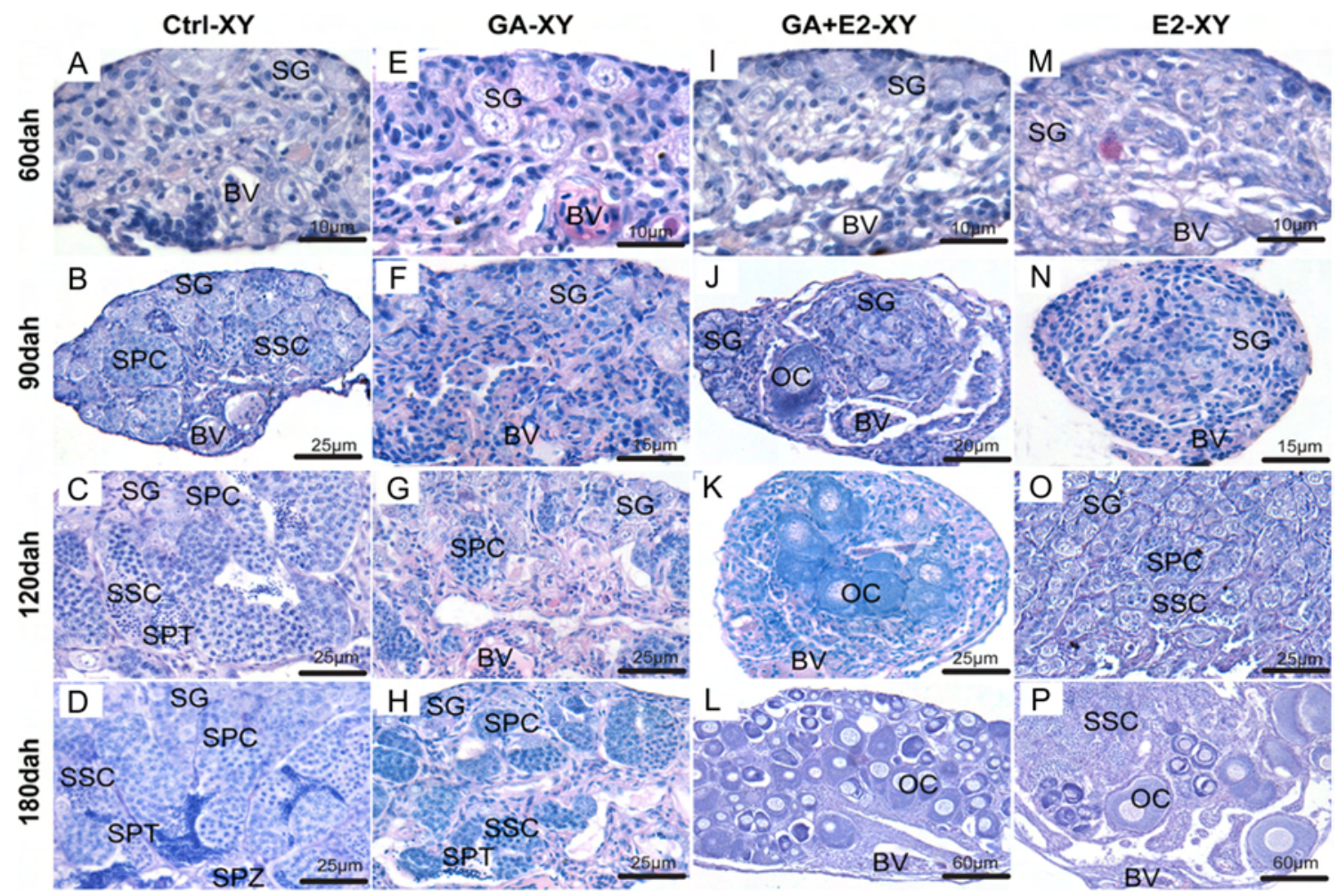

\section{Figure 1}

Histological observations of gonads from XY control and treatment fish at 60,90, 120 and 180 dah. In XY control gonad, only spermatogonia were observed at 60 dah, primary and secondary spermatocytes appeared at 90 dah, spermatids appeared at 120 dah and spermatozoa appeared 180 dah (A, B, C and D). In GA XY fish, only spermatogonia were observed at 60 and 90 dah, primary spermatocytes appeared at 120 dah, secondary spermatocytes and spermatids appeared at 180 dah (E, F, G and H). In GA+E2 XY gonad, only testicular tissue was observed at 60 dah; one oocyte appeared adjacent to the blood vessel at 90 dah; several oocytes appeared in the central area of the gonad at 120 dah and only ovarian tissue was observed at 180 dah (I, J, K and L). The SSR induced by E2 treatment alone in XY fish displayed delayed male-to-female sex reversal compared with the GA+E2 XY fish, with testicular tissue observed at 60, 90 and 120 dah, ovotestis with ovarian tissue near blood vessel and testicular tissue opposite to blood vessel observed at 180 dah (M, N, O and P). BV, blood vessel; OC, oocyte; PSC, primary spermatocytes; SG, spermatogonia; SPT, spermatids; SPZ, spermatozoa; SSC, secondary spermatocytes.

$\begin{aligned} & \text { http://joe.endocrinology-journals.org } \\ & \text { DOI: } 10.1530 / J O E-16-0551\end{aligned} \quad$ Printed in Great Britain
Published by Bioscientifica Ltd 


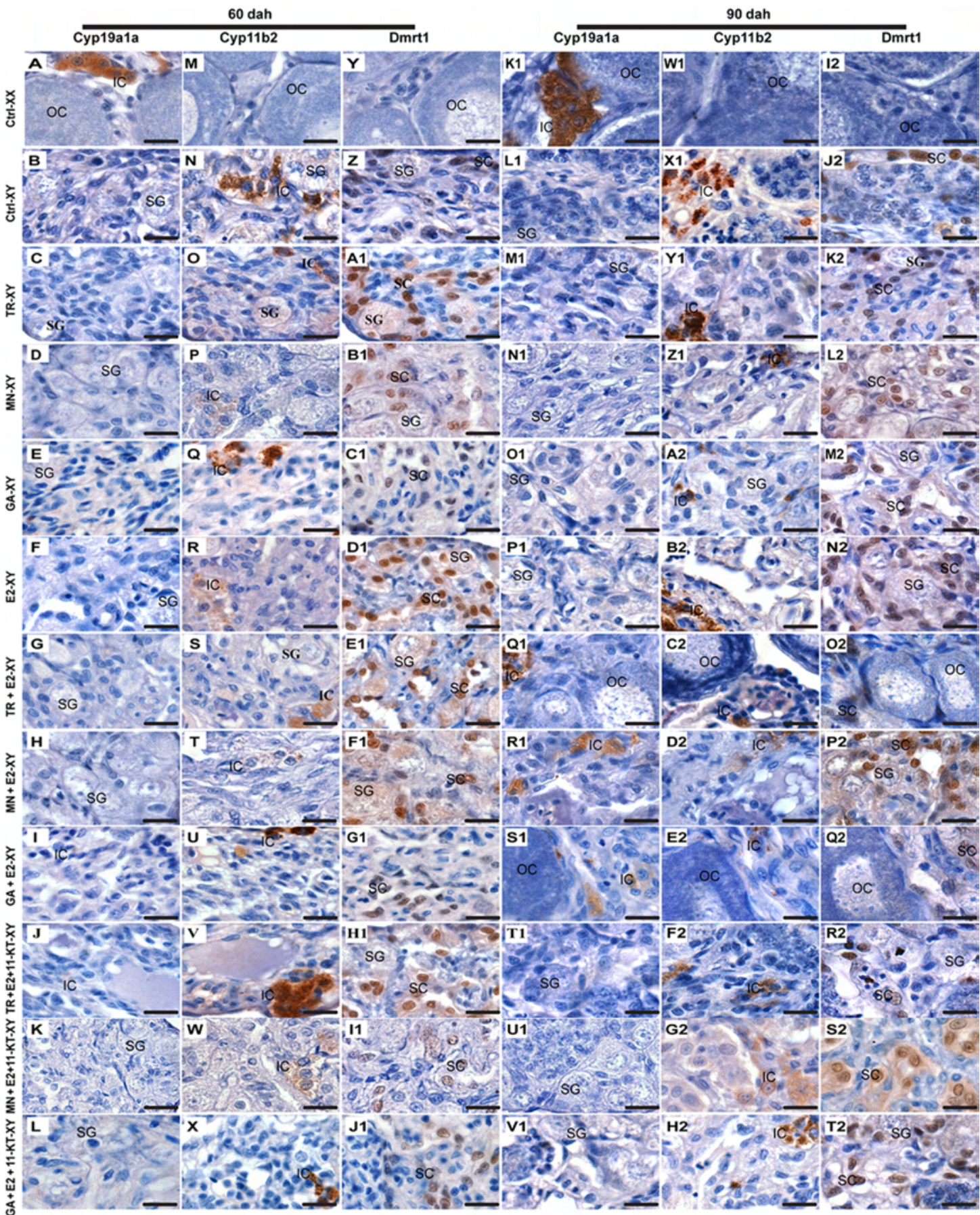

\section{Figure 2}

Expression of Cyp19a1a, Cyp11b2 and Dmrt1 in the gonad of XX, XY control and XY treatment fish at 60 and 90 dah by immunohistochemistry. The XY fish were treated by TR, MN and GA (150 $\mu \mathrm{g} / \mathrm{g}$ diet) alone or in combination with E2 (150 $\mu \mathrm{g} / \mathrm{g}$ diet) and rescued by administration of $11-\mathrm{KT}(150 \mu \mathrm{g} / \mathrm{g}$ diet) from 30 to $90 \mathrm{dah}$, and then fed with normal commercial diet. The control fish were raised in steroid-free water and fed with normal commercial diet. Cyp19a1a (A-L and K1-V1) was found to be expressed in the interstitial cells of the gonad of the control XX at 60 dah (A), and control XX (K1), $\mathrm{TR}+\mathrm{E} 2(\mathrm{Q} 1), \mathrm{MN}+\mathrm{E} 2(\mathrm{R} 1)$ and GA+E2 fish (S1) at 90 dah. Cyp11b2 (M-X and W1-H2) was found to be expressed in the interstitial cells of the gonad of the control $X Y(N$ and $X 1), T R(O$ and $Y 1), M N(P$ and $Z 1), G A(Q$ and $A 2), E 2$ ( $R$ and $B 2), T R+E 2$ (S and $C 2), M N+E 2$ (T and D2), GA+E2 (U and E2), $\mathrm{TR}+\mathrm{E} 2+11-\mathrm{KT}(\mathrm{V}$ and $\mathrm{F} 2), \mathrm{MN}+\mathrm{E} 2+11-\mathrm{KT}(\mathrm{W}$ and $\mathrm{G} 2)$ and $\mathrm{GA}+\mathrm{E} 2+11-\mathrm{KT} \mathrm{XY}$ fish (X and H2) at 60 and 90 dah. Dmrt1 (Y-J1 and I2-T2) was found to be expressed in Sertoli cells of the gonads of the control $X Y$ ( $Z$ and J1), TR (A1 and K2), MN (B1 and L2), GA (C1 and M2), E2 (D1 and N2), TR+E2 (E1 and $\mathrm{O} 2), \mathrm{MN}+\mathrm{E} 2$ (F1 and P2), GA+E2 (G1 and Q2), TR+E2+11-KT (H1 and R2), MN + E2 + 11-KT (I1 and S2) and GA+E2+11-KT XY fish (X and H2) at 60 and 90 dah. dah, day after hatching. The positive signal corresponds to the brownish color. IC, interstitial cells; OC, oocyte; SC, Sertoli cell; SG, spermatogonia. Scale bar: $5 \mu \mathrm{m}$.

http://joe.endocrinology-journals.org DOI: 10.1530/JOE-16-0551
(C) 2017 Society for Endocrinology Printed in Great Britain
Published by Bioscientifica Ltd 
A
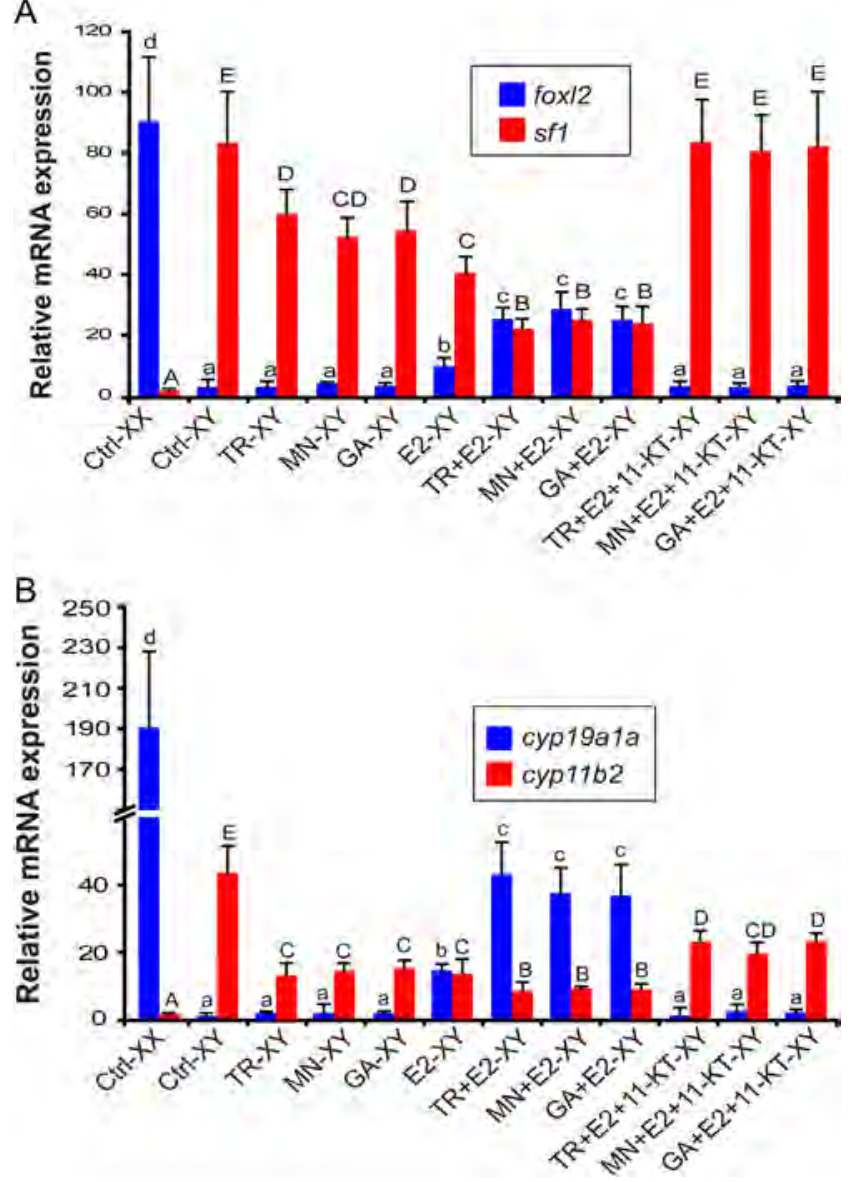

Figure 3

Gene expression in $X X, X Y$ control and $X Y$ treatment fish at 90 dah by real-time PCR. foxI 2 was significantly upregulated in the gonads of the $E 2, T R+E 2, M N+E 2$ and GA $+E 2 X Y$ fish at 90 dah, compared with that of the control $X Y$ and the other $X Y$ treatment fish. The expression of $s f 1$ was significantly downregulated in gonads of the TR, MN, GA, E2, TR +E2, $\mathrm{MN}+\mathrm{E} 2$ and $\mathrm{GA}+\mathrm{E} 2 \mathrm{XY}$ fish, compared with that of 11-KT rescue and the control $X Y$ fish (A). The expression of cyp19a1a displayed similar pattern to that of fox/2. The expression of cyp $11 \mathrm{~b} 2$ was significant downregulated in gonads of all treatment $X Y$ fish, compared with that of the control XY fish (B). Data were expressed as the mean \pm S.D. $(n=6)$. The expression level was normalized using the geometric mean of the levels of three internal control genes ( $\beta$-actin, gapdh and eEF1A1a). Different letters above the error bar indicate significant difference $(P<0.05)$ as determined by one-way ANOVA followed by Duncan post hoc test.

testicular tissue with spermatogonia was observed at 60 dah, 1-3 oocytes were observed adjacent to the blood vessel in the ovotestis at 90 dah, 9-23 oocytes appeared in the central area of the gonad at 120 dah and only ovarian tissue was observed at 180 dah (Fig. 1I, J, K and L). The E2 SSR fish displayed delayed male-to-female sex reversal compared with the GA+E2 SSR fish, with testicular tissue observed at 60, 90 and 120 dah, ovotestis with ovarian tissue near blood vessel and testicular tissue opposite to blood vessel observed at 180 dah (Fig. 1M, N, O and P).
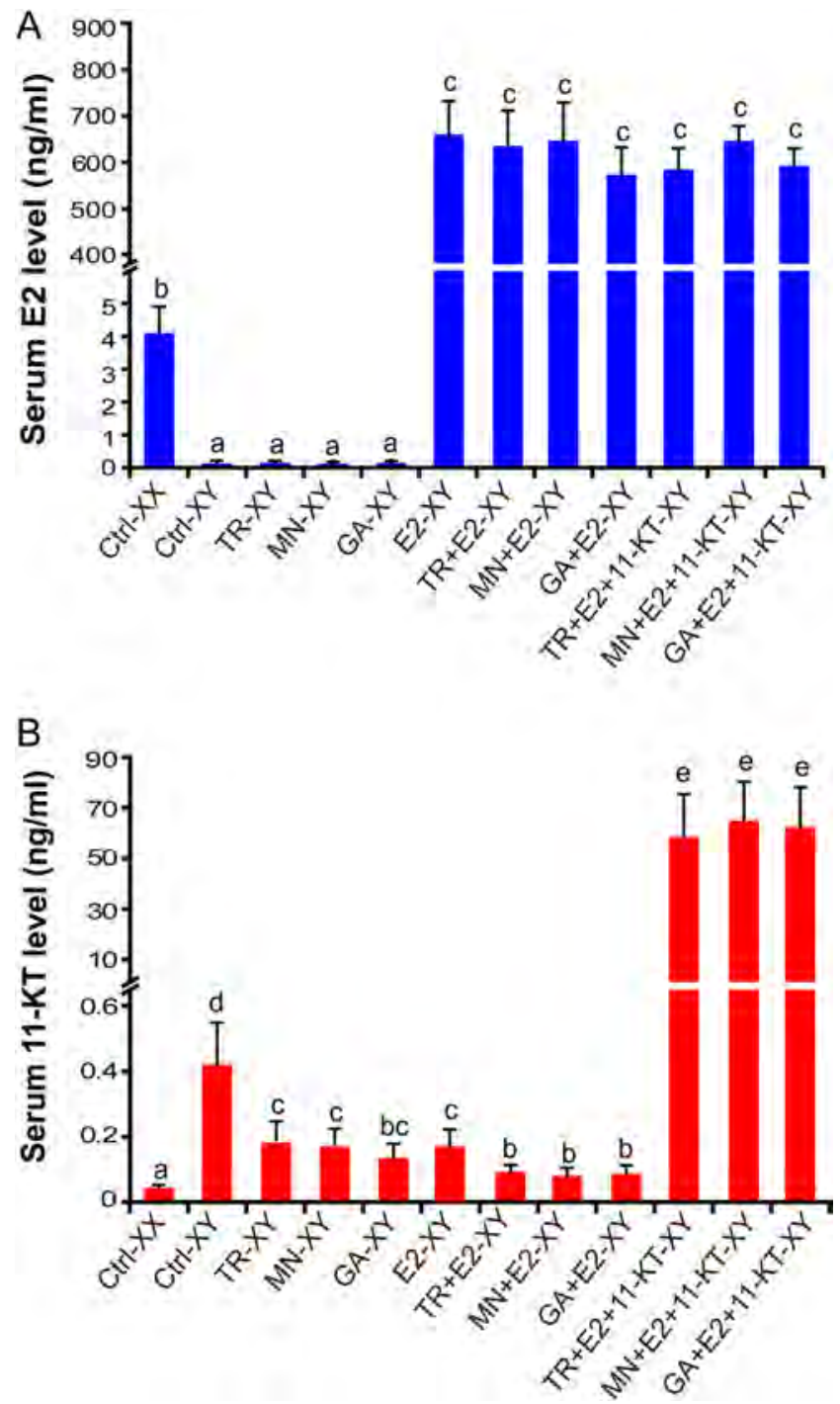

Figure 4

Serum E2 (A) and 11-KT (B) level of XX, XY control and XY treatment fish at 90 dah by enzyme immunoassay. The serum E2 level was significantly upregulated in E2, TR+E2, MN+E2, GA+E2, TE + E2 + 11-KT, $M N+E 2+11-K T$ and $G A+E 2+11-K T X Y$ fish, compared with that of control $X Y, T R, M N$ and GA XY fish at 90 dah (A). The serum 11-KT level was significantly upregulated in $\mathrm{TE}+\mathrm{E} 2+11-\mathrm{KT}, \mathrm{MN}+\mathrm{E} 2+11-\mathrm{KT}$ and $\mathrm{GA}+\mathrm{E} 2+11-\mathrm{KT} \mathrm{XY}$ fish, but significantly downregulated in E2, TR, MN, GA, TR+E2, MN+E2 and $\mathrm{GA}+\mathrm{E} 2$ treatment $\mathrm{XY}$ fish at 90 dah, compared with that of control $X Y$ fish. However, the serum 11-KT level of the TR, MN, E2 fish was significantly higher than that of the GA, TR+E2, MN+E2 and GA+E2 treatment XY fish (B). Data were expressed as the mean \pm S.D. $(n=6)$. Different letters above the error bar indicate significant difference $(P<0.05)$ as determined by one-way ANOVA followed by Duncan post hoc test.

\section{Gene expression during SSR in XY fish treated from 30 to 90 dah}

The $\mathrm{TR}+\mathrm{E} 2, \mathrm{MN}+\mathrm{E} 2$ and $\mathrm{GA}+\mathrm{E} 2$ SSR fish were used for gene expression profile and serum hormone level analyses. By IHC, Cyp19a1a was found to be expressed in the interstitial cells of the ovary in the control XX

Published by Bioscientifica Ltd. 
Cyp19a1a
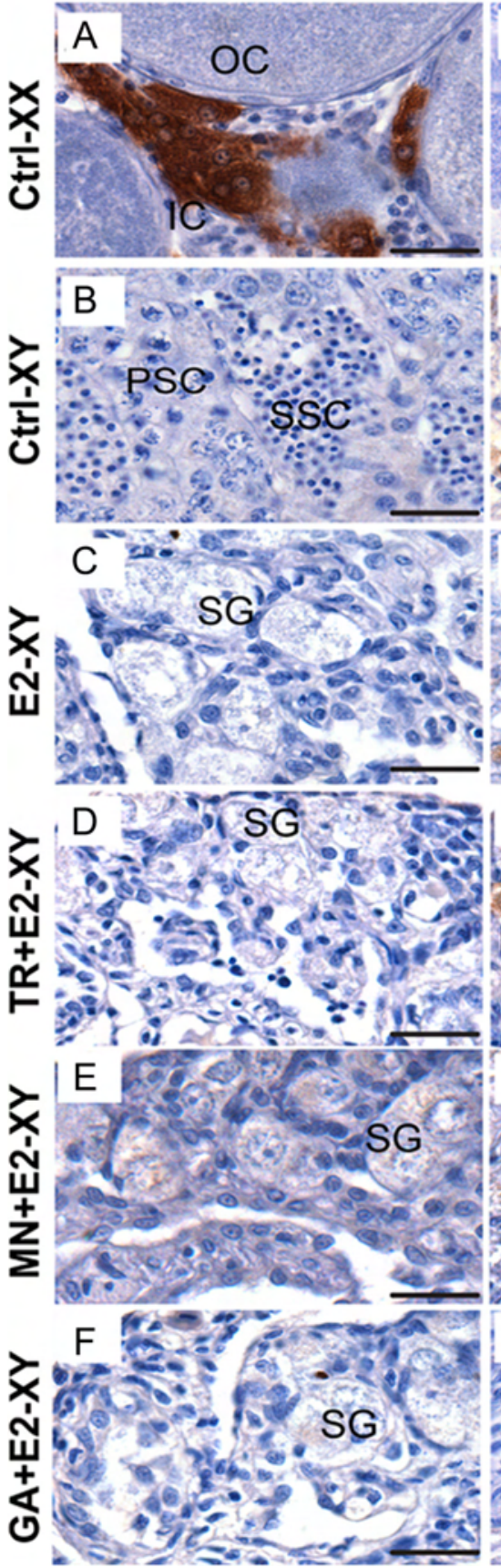

Cyp11b2
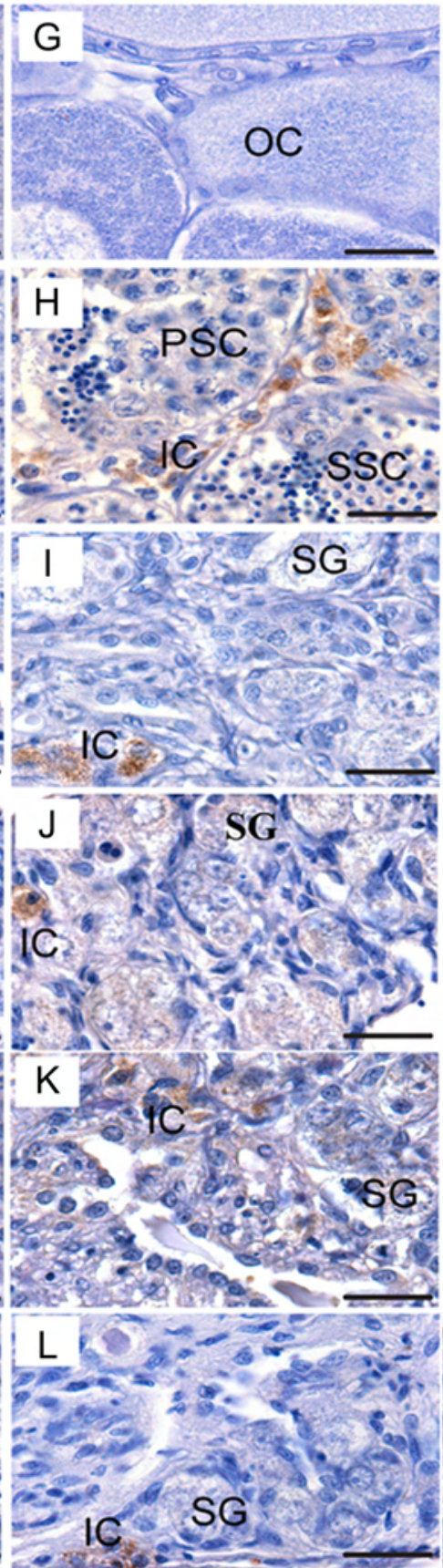

Dmrt1
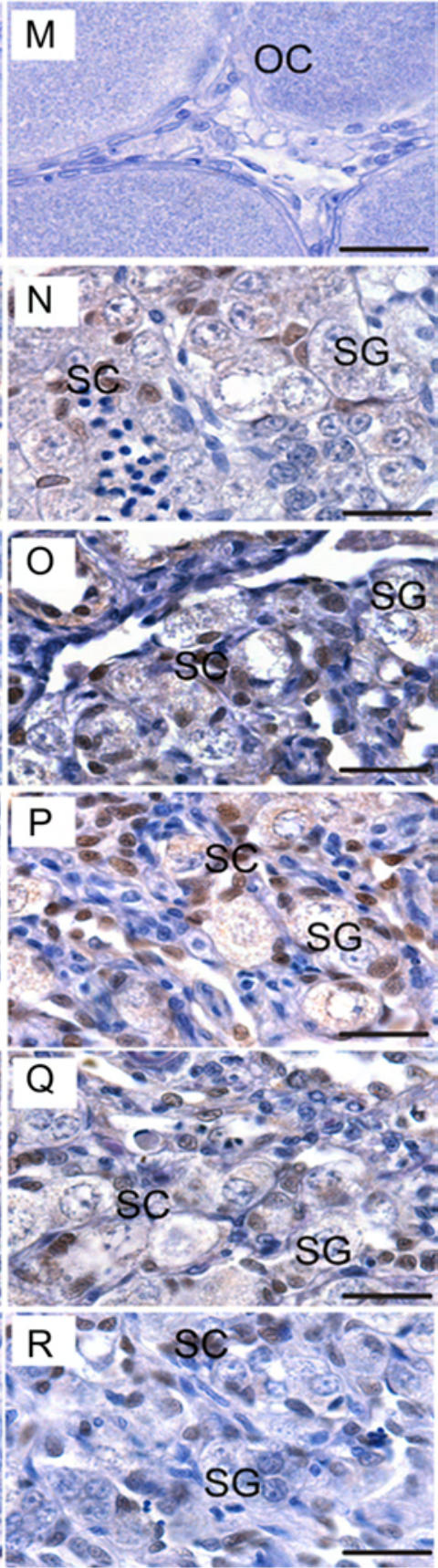

Figure 5

Expression of Cyp19a1a, Cyp11b2 and Dmrt1 in gonad of XX, XY control and XY treatment fish at 120 dah by immunohistochemistry. The XY fish were treated by E2 alone $(150 \mu \mathrm{g} / \mathrm{g}$ diet) or in combination with TR, MN and GA ( $150 \mu \mathrm{g} / \mathrm{g}$ diet) from 60 to 120 dah, and then fed with normal commercial diet till 180 dah. The control fish were raised in steroid-free water and fed with normal commercial diet. Cyp19a1a (A, B, C, D, E and F) was found to be expressed in the interstitial cells of the control XX (A). Cyp11b2 (G, H, I, J, K and L) was found to be expressed in the Leydig cells of the control $X Y, E 2, T R+E 2, M N+E 2$ and GA+E2 gonads at 120 dah $(H, I, J, K$ and $L)$. Dmrt1 $(M, N, O, P, Q$ and $R)$ was found to be expressed in Sertoli cells of the control $X Y, E 2, T R+E 2, M N+E 2$ and $G A+E 2$ gonads at 120 dah (N, O, P, Q and R). The positive signal corresponds to the brownish color. IC, interstitial cells; OC, oocytes; PSC, primary spermatocytes; SC, Sertoli cells; SG, spermatogonia; SSC, secondary spermatocytes. Scale bar: $10 \mu \mathrm{m}$.

http://joe.endocrinology-journals.org DOI: 10.1530/JOE-16-0551
๑ 2017 Society for Endocrinology Printed in Great Britain
Published by Bioscientifica Ltd 
fish, but not in the testis of the control $\mathrm{XY}, \mathrm{TR}, \mathrm{MN}$ and GA treatment XY fish at 60 dah (Fig. 2A, B, C, D, E, F, G, H, I, J, K and L). Cyp11b2 and Dmrt1 were found to be expressed in the Leydig and Sertoli cells of the testis, respectively, in the control XY, TR, MN and GA treatment XY fish (Fig. 2N, O, P, Q, R, S, T, U, V, W, $\mathrm{X}$ and $\mathrm{Z}, \mathrm{A} 1, \mathrm{~B} 1, \mathrm{C} 1, \mathrm{D} 1, \mathrm{E} 1, \mathrm{~F} 1, \mathrm{G} 1, \mathrm{H} 1, \mathrm{I} 1, \mathrm{~J} 1)$, but not in the ovary of the control XX fish (Fig. $2 \mathrm{M}$ and $\mathrm{Y}$ ). Interestingly, Cyp19a1a was found to be expressed in the ovary of the control XX fish and the ovotestis of the $\mathrm{TR}+\mathrm{E} 2, \mathrm{MN}+\mathrm{E} 2$ and $\mathrm{GA}+\mathrm{E} 2 \mathrm{SSR}$ fish (Fig. 2K1 and Q1, R1, S1), but not in the testis of the control XY, $\mathrm{TR}, \mathrm{MN}, \mathrm{GA}, \mathrm{E} 2, \mathrm{TR}+\mathrm{E} 2+11-\mathrm{KT}, \mathrm{MN}+\mathrm{E} 2+11-\mathrm{KT}$ and GA+E2+11-KT XY fish (Fig. 2L1, M1, N1, O1, P1 and T1, U1, V1). Cyp11b2 and Dmrt1 were found to be expressed in the ovotestis of the TR+E2, MN+E2, GA+E2 SSR fish and in the testis of the control XY, TR, MN, GA, E2, $\mathrm{TR}+\mathrm{E} 2+11-\mathrm{KT}, \mathrm{MN}+\mathrm{E} 2+11-\mathrm{KT}$ and $\mathrm{GA}+\mathrm{E} 2+11-\mathrm{KT} \mathrm{XY}$ fish (Fig. 2X1, Y1, Z1, A2, B2, C2, D2, E2, F2, G2, H2 and J2, K2, L2, M2, N2, O2, P2, Q2, R2, S2, T2), but not in the ovary of the control XX fish (Fig. 2W1 and I2). Later, Cyp19a1a was detected in the ovary of the SSR XY fish at 180 dah, whereas Cyp11b2 and Dmrt1 were disappeared. Unexpectedly, Cyp19a1a, Cyp11b2 and Dmrt1 were found to be expressed simultaneously in the ovotestis of E2 XY fish (Supplementary Fig. 1).

Consistently, the expression of foxl2 in the gonad of the $\mathrm{TR}+\mathrm{E} 2, \mathrm{MN}+\mathrm{E} 2$ and $\mathrm{GA}+\mathrm{E} 2$ SSR fish was significantly higher than that of the $\mathrm{E} 2 \mathrm{XY}$, control XY, TR, MN, GA, $\mathrm{TR}+\mathrm{E} 2+11-\mathrm{KT}, \mathrm{MN}+\mathrm{E} 2+11-\mathrm{KT}$ and $\mathrm{GA}+\mathrm{E} 2+11-\mathrm{KT} \mathrm{XY}$ fish, which displayed no significant difference among themselves, except E2 XY fish, by real-time PCR. In contrast, the expression of $s f 1$ in $\mathrm{TR}+\mathrm{E} 2, \mathrm{MN}+\mathrm{E} 2$ and $\mathrm{GA}+\mathrm{E} 2 \mathrm{SSR}$ fish was significantly lower than that of TR, MN, GA, E2 $\mathrm{XY}$ fish, which was significantly lower than that of the 11-KT rescued and control XY fish (Fig. 3A). However, the expression of $d m r t 1$ and $g s d f$ in the gonad of the E2, TR, MN and GA XY fish was significantly higher than that of the $\mathrm{TR}+\mathrm{E} 2, \mathrm{MN}+\mathrm{E} 2, \mathrm{GA}+\mathrm{E} 2, \mathrm{TR}+\mathrm{E} 2+11-\mathrm{KT}, \mathrm{MN}+\mathrm{E} 2+11-\mathrm{KT}$, $\mathrm{GA}+\mathrm{E} 2+11-\mathrm{KY}$ and control $\mathrm{XY}$ fish, which showed no significant differences among themselves (Supplementary Fig. 2A). The expression of cyp19a1a displayed similar pattern to that of foxl2. The expression of $c y p 11 b 2$ displayed similar pattern to that of $s f 1$, except the 11-KT rescued XY fish, which displayed significantly lower level than that of the control XY fish (Fig. 3B). The expression of cyp26a1 was significantly upregulated, whereas the expression of scp3 was significantly downregulated, in the gonad of the E2, TR, MN and GA XY fish, compared with that of the control XY fish (Supplementary Fig. 2B).
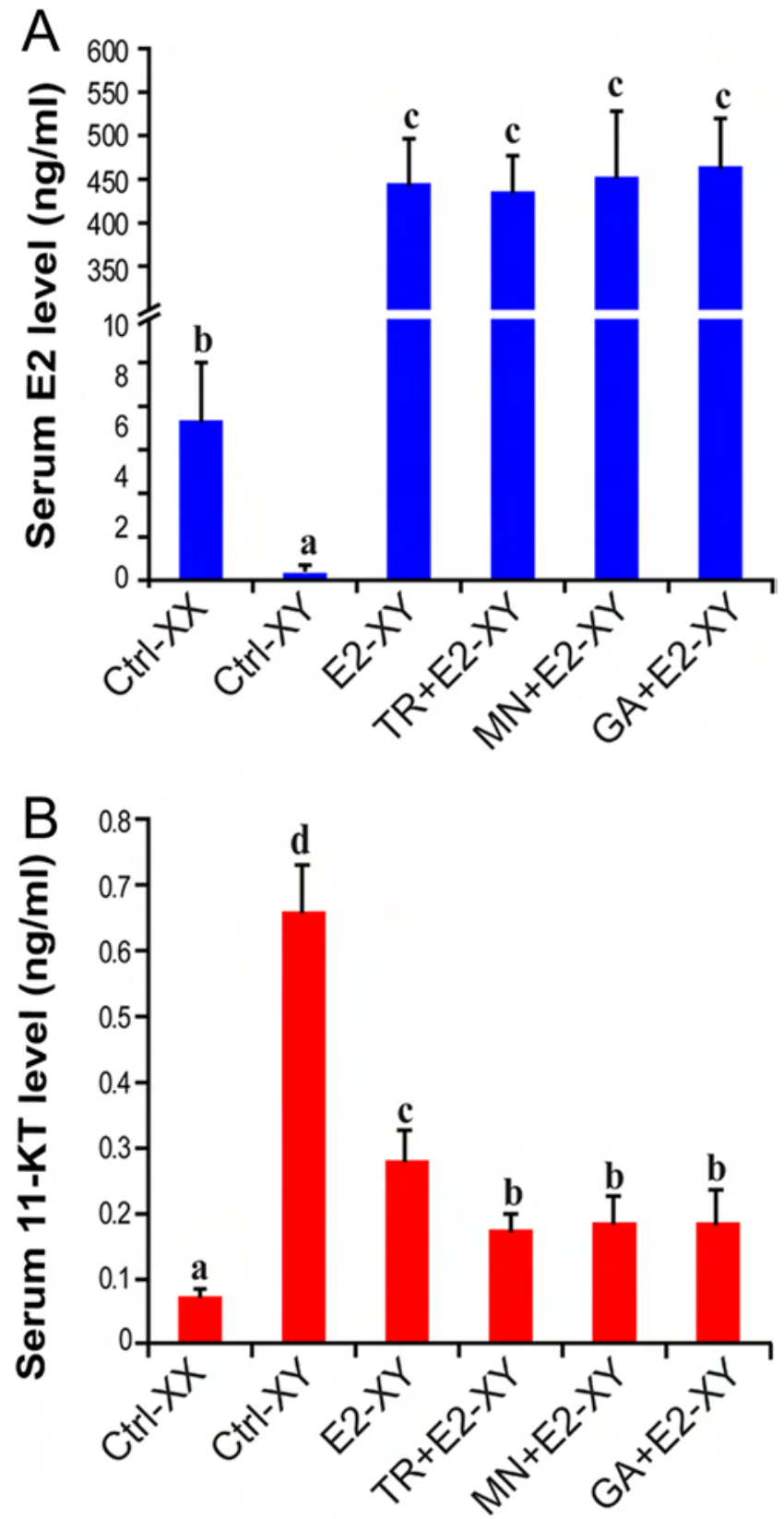

Figure 6

Serum E2 (A) and 11-KT (B) level in XX, XY control and $X Y$ treatment fish at 120 dah by enzyme immunoassay. The serum E2 level was significantly upregulated in the E2, TR+E2, MN +E2 and GA+E2 XY fish, compared with that of control $X X$ and $X Y$ fish, whereas the serum 11-KT level was significantly downregulated in the E2, TR+E2, MN+E2 and GA+E2 XY fish, compared with that of the control $X Y$ fish. Data were expressed as the mean \pm s.D. $(n=6)$. Different letters above the error bar indicate significant difference $(P<0.05)$ as determined by one-way ANOVA followed by Duncan post hoc test.

\section{Serum E2 and 11-KT levels of XY fish treated from 30 to 90 dah}

EIA analysis showed that the serum E2 levels of E2, TR $+\mathrm{E} 2$, $\mathrm{MN}+\mathrm{E} 2, \mathrm{GA}+\mathrm{E} 2, \mathrm{TR}+\mathrm{E} 2+11-\mathrm{KT}, \mathrm{MN}+\mathrm{E} 2+11-\mathrm{KT}$ and

Published by Bioscientifica Ltd 


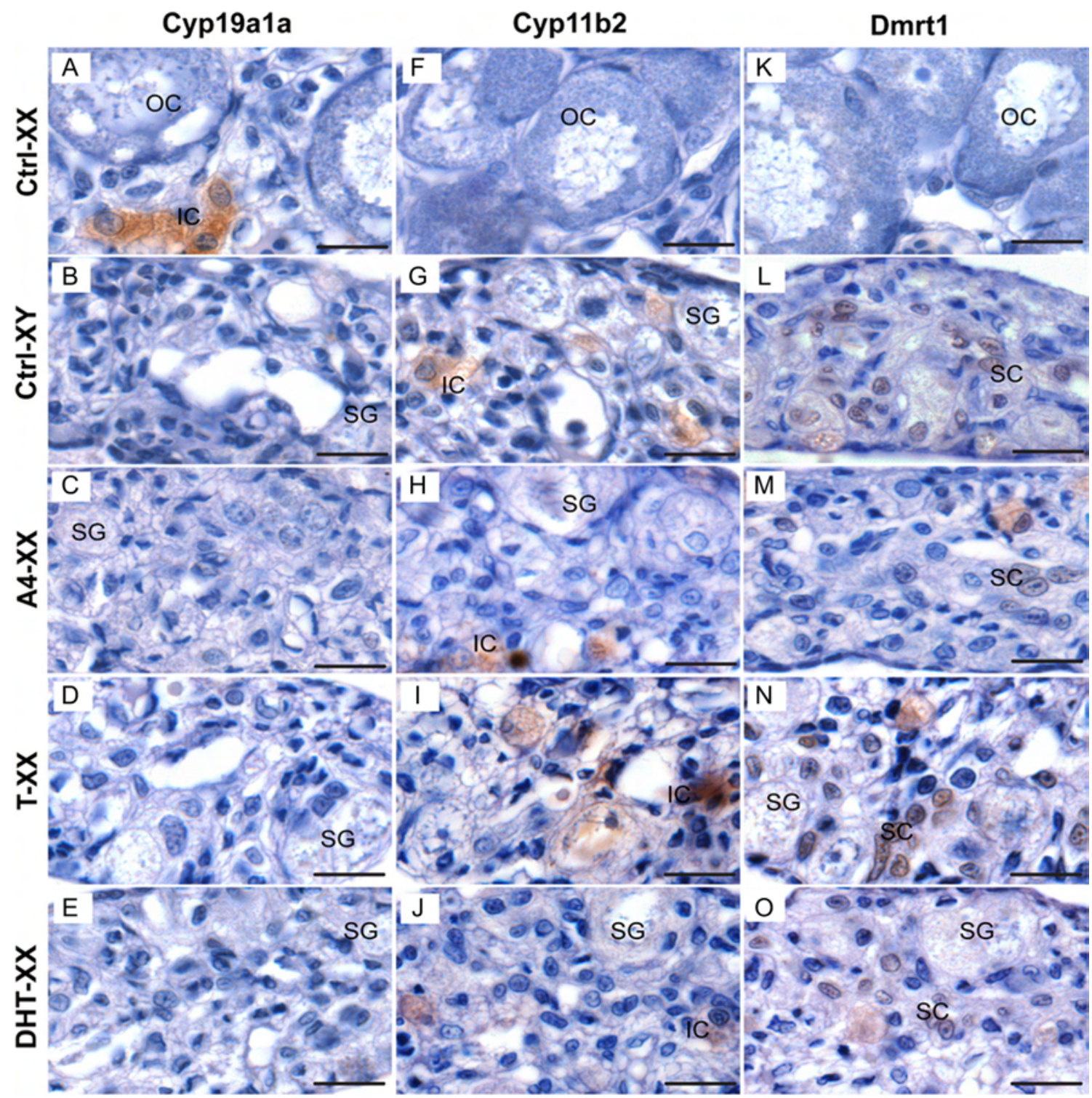

Figure 7

Expression of Cyp19a1a, Cyp11b2 and Dmrt1 in gonads of XX, XY control and XX treatment fish at 30 dah by immunohistochemistry. The XX fish were exposed to A4, testosterone and DHT ( $50 \mu \mathrm{g} / \mathrm{L}$ water) from 0 to $5 \mathrm{dah}$, and then fed with A4, testosterone and DHT ( $50 \mu \mathrm{g} / \mathrm{g}$ diet) until $30 \mathrm{dah}$. The control fish were raised in steroid-free water and fed with normal commercial diet. Cyp19a1a was only found to be expressed in the control XX gonad ( $A, B, C, D$ and E). Cyp11b2 and Dmrt1 were found to be expressed in the control $X Y$ and $A 4$, testosterone, DHT XX gonads $(F, G, H, I, J$ and $K, L, M, N, O)$. The positive signal corresponds to the brownish color. IC, interstitial cells; OC, oocytes; SC, Sertoli cells; SG, spermatogonia. Scale bar: $5 \mu \mathrm{m}$.

GA+E2+11-KT XY fish were 140-180 times higher than those of the control XX fish, whereas the control XY, TR, MN and GA XY fish showed no significant difference among themselves at 90 dah (Fig. 4A). In contrast, the serum 11-KT levels of the TR+E2+11-KT, $\mathrm{GA}+\mathrm{E} 2+11-\mathrm{KT}$ and $\mathrm{MN}+\mathrm{E} 2+11-\mathrm{KT} \mathrm{XY}$ were $140-160$ times higher than those of the control XY, TR, MN, GA, $\mathrm{E} 2, \mathrm{TR}+\mathrm{E} 2, \mathrm{MN}+\mathrm{E} 2$ and $\mathrm{GA}+\mathrm{E} 2 \mathrm{XY}$ fish at 90 dah. The serum 11-KT levels of TR, MN, GA and E2 XY fish were significantly lower than those of the control XY fish.
The serum 11-KT levels of TR+E2, MN+E2 and GA+E2 SSR fish were significantly lower than those of control XY and other treatment XY fish, except GA XY fish, at 90 dah (Fig. 4B).

SSR rate, gene expression and serum hormone levels of $\mathrm{XY}$ fish treated from 60 to 120 dah

When the gonad phenotype was examined histologically at 180 dah, all control XY fish developed as male with http://joe.endocrinology-journals.org DOI: 10.1530/JOE-16-0551
๑ 2017 Society for Endocrinology Printed in Great Britain
Published by Bioscientifica Ltd 
normal testis and all control XX fish developed as female with normal ovary. Treatment of XY fish with E2 alone or in combination with $\mathrm{MN}$ and GA resulted in no male-to-female SSR, whereas with $\mathrm{TR}+\mathrm{E} 2$, resulted in 3.3\% SSR (Supplementary Table 3).

By IHC, Cyp19a1a was found to be expressed in the gonad of the control XX fish at 120 dah, and the control $\mathrm{XX}, \mathrm{TR}+\mathrm{E} 2 \mathrm{XY}$ SSR fish at 150 dah, but not in the gonad of the control $\mathrm{XY}, \mathrm{E} 2, \mathrm{TR}+\mathrm{E} 2, \mathrm{MN}+\mathrm{E} 2$ and $\mathrm{GA}+\mathrm{E} 2 \mathrm{XY}$ fish (Fig. 5A, B, C, D, E, F and Supplementary Fig. 3A, B, C, $\mathrm{D}, \mathrm{E}, \mathrm{F})$. Cyp11b2 and Dmrt1 were found to be expressed in the gonad of the control $\mathrm{XY}, \mathrm{E} 2, \mathrm{TR}+\mathrm{E} 2, \mathrm{MN}+\mathrm{E} 2$ and $\mathrm{GA}+\mathrm{E} 2 \mathrm{XY}$ fish, but not in the gonad of control XX fish, at 120 and 150 dah (Fig. 5G, H, I, J, K, L, M, N, O, P, Q, $\mathrm{R}$ and Supplementary Fig. 3H, I, J, K, L, M, N, O, P, Q, R).

EIA analysis showed that the serum E2 level of the E2, $\mathrm{GA}+\mathrm{E} 2, \mathrm{MN}+\mathrm{E} 2$ and $\mathrm{TR}+\mathrm{E} 2 \mathrm{XY}$ fish was 90 times higher than that of the control XX fish at 120 dah. The serum 11-KT level of the E2, GA+E2, MN+E2 and TR+E2 XY fish was significantly lower than that of the control XY fish, but significantly higher than that of the control $\mathrm{XX}$ fish (Fig. 6A and B). Although at 150 dah, 30 days after the withdrawal of the exogenous E2, the serum E2 of $\mathrm{XY}$ treatment fish dropped to a level lower than that of control XX fish, and the serum 11-KT level was still lower than that of control XY fish (Supplementary Fig. 3S and T).

\section{Treatment of XX fish by A4, testosterone and DHT from 5 to 30 dah resulted in PSR}

PSR of XX fish was successfully induced by A4 (sex reversal rate, 2/10), testosterone (9/10) and DHT (8/10) treatment. The sex reversed XX fish were used for gene expression profile analysis. By IHC, Cyp19a1a was found to be expressed in the gonad of the control XX fish, but not in the control XY, A4, testosterone and DHT $\mathrm{XX}$ fish at 30 dah (Fig. 7A, B, C, D and E). Cyp11b2 and Dmrt1 were found to be expressed in the gonad of the control XY, A4, testosterone and DHT XX fish, but not in the control XX fish (Fig. 7F, G, H, I, J and $\mathrm{K}, \mathrm{L}, \mathrm{M}, \mathrm{N}, \mathrm{O}$ ).

\section{Discussion}

In fish, estrogens are synthesized during the key time of sex differentiation in females and play a critical role in sex differentiation and maintenance. In contrast, whether androgens are synthesized in the undifferentiated gonad to mediate sex differentiation in male is still controversial.
In medaka, tilapia and some other fishes, Cyp11b2 and $11 \beta$-HSD2 are not detected before the morphological differentiation of the testis (Nakamura et al. 1998, Ijiri et al. 2008). However, in pejerrey, cyp11b1 and 11ß-HSD2 are expressed, and androgens are synthesized in male undifferentiated gonads (Hattori et al. 2009, Blasco et al. 2010, 2013, Fernandino et al. 2012, 2013). In both cases, once the gonadal morphological differentiation has been started, Cyp11b1/2, 11ß-HSD2 and androgens are significantly upregulated (Nakamura et al. 1998, Vizziano et al. 2007, Blasco et al. 2010). Male-tofemale sex reversal is restricted to morphologically undifferentiated stage by administration of exogenous estrogens (Guiguen et al. 1999, Kobayashi \& Iwamatsu 2005, Chen et al. 2016). This led us to hypothesize that androgens antagonize the exogenous estrogensinduced male-to-female SSR after gonadal morphological differentiation.

\section{Androgens are essential for male sex maintenance and antagonize E2-induced male-to-female sex reversal}

In mammals, TR, MN and GA are the inhibitors of 3 $\beta$-HSD, Cyp11b2 and 11 $\beta$-HSD, respectively (Marandici \& Monder 1993, Villeneuve et al. 2008, Rigel et al. 2010). In this study, TR, MN and GA treatment alone from 30 to 90 dah resulted in no sex reversal in $\mathrm{XY}$ fish as demonstrated by gonadal histology and the absence of Cyp19a1a expression at all time points checked. Consistently, no significant differences in the gonadal expression of foxl2 and cyp19a1a mRNA and serum E2 level were detected compared with control XY fish. As expected, a significant decrease of $c y p 11 b 2$ mRNA and serum 11-KT level were detected in TR, MN and GA XY fish even though no sex reversal was observed, indicating that downregulation of endogenous androgen level alone could not induce male-to-female SSR. In contrast, treatment with E2 alone from 30 to 90 dah resulted in $8.3 \%$ male-to-female SSR in XY fish even though the fish displayed similar serum 11-KT level and cyp11b2 expression to that of the TR, MN and GA XY fish. These results indicated that E2 has the same potential to inhibit androgen production as TR, MN and GA. Moreover, E2 has the ability to promote ovarian differentiation (Guiguen et al. 1999, Nagahama 2000), which was not possessed by TR, MN and GA. Interestingly, when TR, MN and GA were combined with E2, much higher rate of SSR was induced compared with that of the E2 XY fish. Further downregulation of serum 11-KT levels and cyp $11 b 2$ expression, compared with that of the $\mathrm{E} 2 \mathrm{XY}$ fish, were detected in TR+E2, MN+E2 and GA+E2 SSR fish,

Published by Bioscientifica Ltd. 
indicating double suppression of E2 and these inhibitors to androgen production. The sex reversal and gonadal gene expression were rescued by the administration of exogenous 11-KT. No differences in serum E2 level were observed for $\mathrm{E} 2, \mathrm{TR}+\mathrm{E} 2, \mathrm{MN}+\mathrm{E} 2$ and $\mathrm{GA}+\mathrm{E} 2$ treatment fish at the end of the treatment. However, very low sex reversal rate and much longer sex reversal time were observed in E2 treatment fish compared with TR+E2, $\mathrm{MN}+\mathrm{E} 2$ and GA+E2 treatment fish. This might be attributed to the significantly higher level of serum 11-KT in E2 XY fish compared with the other three treatment groups. These results indicated that E2 was essential for inducing male-to-female sex reversal, as demonstrated in the previous studies (Guiguen et al. 1999, Nagahama 2000, Kobayashi et al. 2003, Nakamura et al. 2003, Lee et al. 2004, Wu et al. 2008). Androgens antagonized exogenous E2-induced sex reversal of the XY fish with differentiated testis.

Treatment of $\mathrm{XY}$ fish with $\mathrm{E} 2, \mathrm{TR}+\mathrm{E} 2, \mathrm{MN}+\mathrm{E} 2$ and GA+E2 from 60 to 120 dah resulted in no maleto-female SSR, even though the serum E2 level of the treatment fish was significantly higher than that of the control XX fish and the serum 11-KT level was significantly lower than that of control XY fish at 120 dah. The androgen level might be not low enough to allow E2 to induce sex reversal in these XY fish. Only $3.3 \%$ of the TR +E2 XY fish displayed SSR at 150 dah. These results indicated that it becomes more and more difficult to suppress the gradually increased androgen production so as to induce male-to-female SSR during testicular development. Taken together, our results highlighted the critical roles of endogenous androgens in male sex maintenance.

Our hypothesis is also supported by the study in protandrous black porgy, in which the digonic gonad functions as testis for the first 2 years of life and male-tofemale natural sex change occurs in the 3rd year (Wu et al. 2008). Male-to-female sex change could be induced by exogenous E2 treatment, but could not be maintained after the withdraw of exogenous E2; however, it could be achieved by surgical removal of the testis, in the younger than 2 years age fish (Lee et al. 2004, Wu et al. 2008, 2012, 2016). We suspect that androgens produced in the testicular tissue might be one of the anti-sex-change factors in this hermaphrodic species, as we proved in the gonochoric tilapia with differentiated testis.

Our previous study demonstrates that there is no significant differences in the PSR rate in XY fish treated from 0 to 30 dah by E2 alone (63\%) or in combination with MT (52\%), indicating that E2-induced PSR could not be rescued by simultaneous administration of exogenous androgen (Chen et al. 2016). However, in the present study, the SSR induced by TR+E2, MN+E2 and GA+E2 in $\mathrm{XY}$ fish was successfully rescued by simultaneous administration of exogenous androgen 11-KT or MT. This difference could be explained by the fact that the androgen receptors (ar1 and ar2) are expressed at relatively low levels, almost undetectable until approximately 15 dah in the gonad of the XY fish (Iriji et al. 2008, Tao et al. 2013, Cheng et al. 2015), and therefore, in the PSR fish, there is no receptor to mediate the androgen action during the key period of sex differentiation (5-10 dah), whereas in the SSR fish, androgens bind to the expressed receptors to antagonize E2-induced sex reversal.

\section{Possible mechanism of androgens in male sex maintenance}

In this study, significant up-regulation of foxl2, cyp19a1a was detected in the gonads of the $\mathrm{E} 2, \mathrm{TR}+\mathrm{E} 2, \mathrm{MN}+\mathrm{E} 2$ and $\mathrm{GA}+\mathrm{E} 2$ SSR XY fish at 90 dah, compared with that of control XY fish. After the withdrawal of exogenous E2, Cyp19a1a expression was maintained and even upregulated in the gonads, which in turn, contributed to the higher serum E2 level of the SSR fish at 180 dah, compared with that of the control XY fish (Supplementary Fig. 4). These results indicated that exogenous E2-induced male-to-female sex reversal through increase of endogenous Cyp19a1a expression and estrogen production, as demonstrated in the previous studies (D'Cotta et al. 2001, Ijiri et al. 2008, Guiguen et al. 2010, Pérez et al. 2012, Chen et al. 2016, Wu et al. 2016). However, the upregulation of foxl2 and cyp19a1a expression was rescued by administration of 11-KT in the XY treatment fish (Bhandari et al. 2006, Golan \& Levavi-Sivan 2014), further demonstrated that androgens inhibited foxl2 and cyp19a1a expression to antagonize exogenous E2 induction of SSR in XY fish. On the other hand, the downregulation of $s f 1$ expression could be attributed to the upregulated foxl2 expression in the gonads of the TR+E2, MN+E2 and GA+E2 SSR fish at 90 dah. Transcriptional repression of Foxl2 on $s f 1$ expression was proved in mouse and by our group in tilapia (Kashimada et al. 2011, Takasawa et al. 2014, Xie et al. 2016). However, expression of dmrt1 and gsdf was not concomitantly downregulated in the gonads of the $\mathrm{TR}+\mathrm{E} 2, \mathrm{MN}+\mathrm{E} 2$ and GA+E2 SSR fish at 90 dah, but was downregulated to undetectable level at 180 dah, indicating that estrogen treatment upregulates foxl2 and cyp19a1a, but does not suppress early testicular markers during male-to-female gonadal transdifferentiation as

Published by Bioscientifica Ltd. 


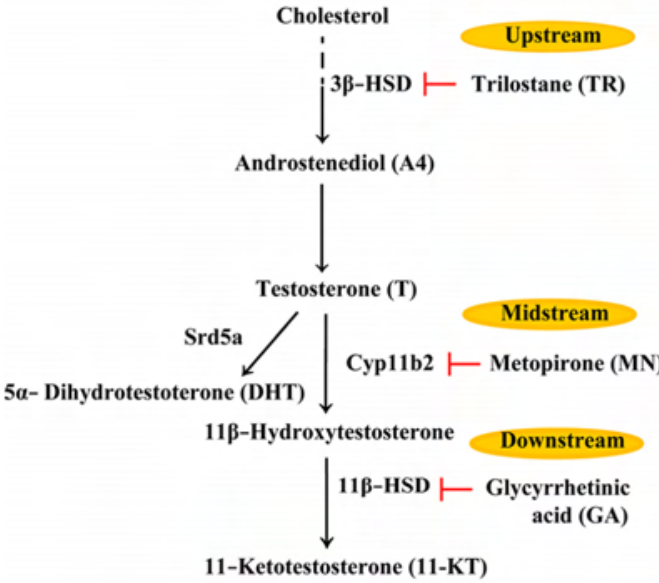

Experiment 3

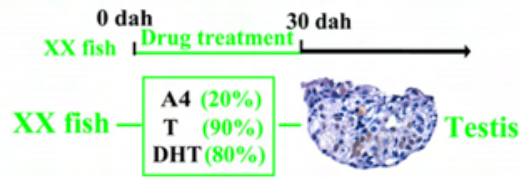

Experiment 1

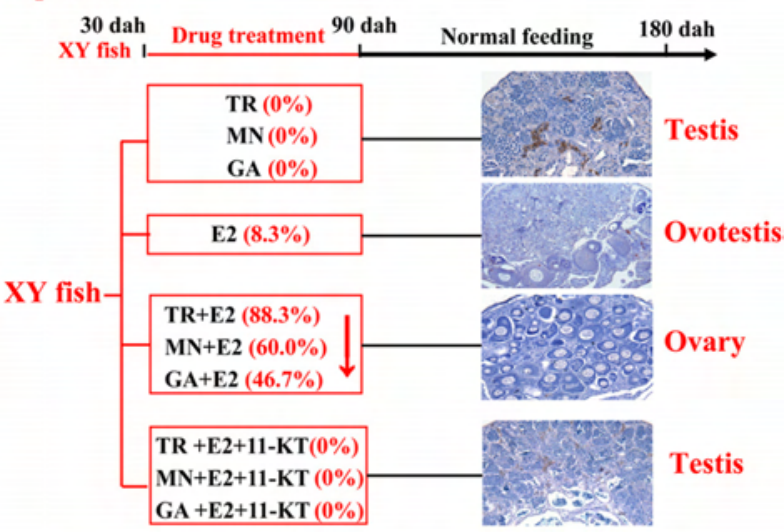

Experiment 2

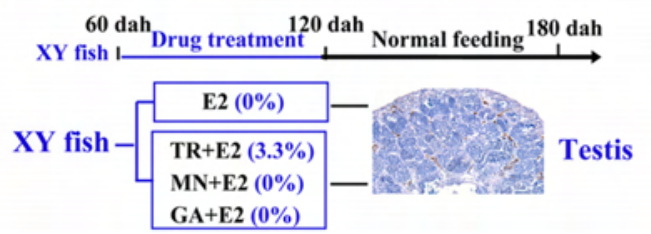

\section{Figure 8}

Schematic representation showing experimental design, results and conclusion. Experiment 1: Inducement of SSR of 30 dah XY fish by androgen inhibitor and/or E2. The results demonstrated that androgens antagonize E2-induced male-to-female SSR. The upper the enzyme located in the steroidogenic pathway, the higher SSR rate was induced with E2 when it was inhibited. The SSR was successfully rescued by 11-KT. Experiment 2: Inducement of SSR of 60 dah XY fish by androgen inhibitor and/or E2. No SSR in E2, MN+E2 and GA+E2 XY fish, and only 3.3\% SSR in TR+E2 XY fish were induced by androgen inhibitor and/or E2 treatment from 60 to 120 dah. The results demonstrated that it was very difficult or even impossible to induce SSR of more differentiated XY fish when androgen levels get higher. Experiment 3: Inducement of PSR in XX fish by exogenous A4, testosterone and DHT treatment. This explains why the upper the enzyme was located in the steroidogenic pathway, the higher SSR rate was achieved when it was inhibited by androgen inhibitor and induced by E2. Androgen precursors could function as androgens to antagonize E2-induced male-to-female sex reversal. Taken together, the results of these three experiment indicated that androgens are essential for male sex maintenance. Androgens antagonize E2 induced male-to-female sex reversal in differentiated testis. The lines and values colored red, blue and green indicate the treatment and induced SSR rate in experiments 1,2 and 3 , respectively.

demonstrated previously (Vizziano-Cantonnet et al. 2008). Taken together, we speculate that androgens antagonize E2-induced SSR of XY fish probably through direct inhibition of E2-induced female pathway gene expression.

\section{The upper the enzyme located in the steroidogenic pathway, the higher SSR rate was induced with E2 when it was inhibited}

A4 is an active androgen and substrate for biosynthesis of functional androgens (DeQuattro et al. 2015). Its product 11-hydroxyandrostenedione (11-OHA) induced sex reversal in the rainbow trout, by downregulation of Cyp19a1a (Govoroun et al. 2001). Testosterone could induce female-to-male sex reversal in medaka (Iwamatsu et al. 2006). DHT increased the levels of 11-KT and decreased the E2/11-KT ratio in both sexes in rainbow fish (Bhatia \& Kumar 2016). In amphibians, female-tomale sex reversal was induced by high concentration of testosterone and DHT (Okada et al. 2008, Phuge \&
Gramapurohit 2014, Xu et al. 2015). In the present study, female-to-male PSR was successfully induced by treatment of XX tilapia from 0 to 30 dah with A4, testosterone and DHT alone. The expression of Dmrt1 and Cyp11b2 was detected and Cyp19a1a was not detected in the gonads of A4, testosterone and DHT treatment fish at 30 dah. These results demonstrate that these androgen precursors could act as androgen in fish.

In this study, male-to-female SSR rate of the TR+E2 XY fish (88.3\%) was higher than that of the $\mathrm{MN}+\mathrm{E} 2(60 \%)$ and the GA+E2 XY fish (46.7\%). The inhibition of 3 $\beta-H S D$ with TR resulted in decreased levels of A4 and testosterone in catfish, the precursors for synthesis of DHT, $11 \beta$-hydroxytestosterone and 11-KT in males (Mishra \& Chaube 2017). In our TR+E2 $\mathrm{XY}$ fish, by inhibition of $3 \beta-\mathrm{HSD}$, the synthesis of A4, testosterone, DHT, 11 $\beta$-hydroxytestosterone and 11-KT was reduced, which significantly attenuated the antagonistic effects on E2-induced SSR. In MN+E2 XY fish, by inhibition of Cyp11b2, the synthesis of $11 \beta$-hydroxytestosterone and 11-KT was reduced, which attenuated the antagonistic effects

Published by Bioscientifica Ltd. 
of androgens on E2-induced sex reversal to a moderate degree and resulted in intermediate SSR rate. In GA+E2 XY fish, by the inhibition of $11 \beta-\mathrm{HSD}$, the synthesis of 11-KT, but not A4, testosterone, DHT and 11ß-hydroxytestosterone, was reduced, which weakly attenuated the antagonistic effect of androgens on E2-induced sex reversal and resulted in the lowest SSR rate. That is, the upper the enzyme is located in the steroidogenic pathway, the higher SSR rate was induced with E2 when it was inhibited.

\section{Orientation of SSR in XY gonad}

In tilapia, the steroidogenic cells (aromatase positive) are firstly observed in a restricted area near the blood vessel at 5 dah, and the ovarian cavity is formed ventral to the ovary proper, opposite to the blood vessel at around 35-50 dah. Similarly, oogenesis proceeds as cluster of oocytes from area adjacent to blood vessel to the opposite in ovary (Nakamura et al. 1989, Strüssmann \& Nakamura 2002, Wang et al. 2007, Ruksana et al. 2011). These studies demonstrate that the differentiation of the bipotential gonad is from the dorsal side (near the blood vessel) to the ventral side in XX fish. In the present study, during male-to-female SSR in XY fish, the first appearance of Cyp19a1a-positive cells and oocytes were observed adjacent to the blood vessel in the ovotestis. The oocytes were gradually increased in numbers occupying the central area with Cyp19a1a-positive cells scattered as clusters of interstitial cells, and finally, the SSR gonad was completely filled with oocytes. These results indicated that transdifferentiation of the differentiated testis proceeds in the same direction like ovarian differentiation, initiated from the area near the blood vessel and ended at the opposite end of the XY gonad. This is different from the female-to-male SSR in XX tilapia, which is from the opposite end to the area near the blood vessel (Sun et al. 2014).

\section{Delayed spermatogenesis in TR, MN and GA treatment $\mathrm{XY}$ gonad}

It is well known that endogenous androgens play critical roles in spermatogenesis during testicular development (Billard 1982, Cavaco et al. 2001, Schulz \& Miura 2002, Ruwanpura et al. 2010). In the present study, the serum 11-KT level of the E2, TR, MN and GA XY fish was significantly lower than that of the control XY fish. Consequently, spermatogenesis was delayed in those XY treatment fish. In mammals, Dmrt1 allows Sertoli cells to participate in retinoic acid (RA) signal to prevent meiosis and promote spermatogonia proliferation in the testis (Jørgensen et al. 2012). Loss of Dmrt1 results in precocious meiosis in male mice (Matson et al. 2010). Our previous study in tilapia demonstrated that cyp26a1, the catabolic enzyme for RA, is critical for the meiotic initiation of germ cells. Inhibition or knockdown of cyp26a1 in XY fish resulted in the upregulation of RA level and earlier initiation of meiosis and spermatogenesis, as demonstrated by upregulation of scp3 (Feng et al. 2015). In the present study, significant upregulation of dmrt1, cyp26a1 and downregulation of $s c p 3$ were detected in the gonads of E2, TR, MN and GA XY fish, compared with that of control XY fish. Taken together, we concluded that the upregulation of dmrt1 might be responsible for the delayed spermatogenesis in the treatment XY fish.

In summary, our study suggests that androgens are critical for male sex maintenance in teleosts. Androgens antagonize E2-induced male-to-female sex reversal in differentiated testis. Therefore, blockage of androgen synthesis and simultaneous administration of E2 can successfully induce the differentiated testis to transdifferentiate into functional ovary (Fig. 8). Our study provides a good model for studying the molecular mechanism of SSR in teleosts.

\section{Supplementary data}

This is linked to the online version of the paper at http://dx.doi.org/10.1530/ JOE-16-0551.

\section{Declaration of interest}

The authors declare that there is no conflict of interest that could be perceived as prejudicing the impartiality of the research reported.

\section{Funding}

This work was supported by the National Natural Science Foundation of China (grant numbers 31630082, 31572609, 31602314 and 91331119); the National Basic Research Program of China (grant number 2012CB723205); the Specialized Research Fund for the Doctoral Program of Higher Education of China (grant number 20130182130003); the Natural Science Foundation Project of Chongqing, Chongqing Science and Technology Commission (grant numbers cstc2014jcyjB80001); the Fundamental Research Funds for the Central Universities (grant number XDJK2014B040, XDJK2016E099, XDJK2016E090 and XDJK2016C157); the China Postdoctoral Science Foundation (grant number 2015M570765, 2016T90830) and Chongqing Postdoctoral Science Foundation (grant number Xm2015028).

\section{Author contribution statement}

H S, T G and L S conceived and designed the experiments; H S, T G, Z L, L C and X J collected the sample; H S, T G and Z L performed the experiments;
๑ 2017 Society for Endocrinology Printed in Great Britain
Published by Bioscientifica Ltd 
H S and T G and L S performed the analyses; D W and H S wrote the paper and $\mathrm{H} \mathrm{S}, \mathrm{T} G, \mathrm{Z} \mathrm{L}$ and $\mathrm{L} S$ contributed equally to this work.

\section{Acknowledgements}

The authors cordially thank Prof. Yoshitaka Nagahama from the National Institute for Basic Biology, Okazaki, Japan for providing the Cyp19a1a antibody.

\section{References}

Benton CB \& Berlinsky DL 2006 Induced sex change in black sea bass. Journal of Fish Biology 69 1491-1503. (doi:10.1111/j.10958649.2006.01212.x)

Bhandari RK, Higa M, Nakamura S \& Nakamura M 2004a Aromatase inhibitor induces complete sex change in the protogynous honeycomb grouper (Epinephelus merra). Molecular Reproduction and Development 67 303-307. (doi:10.1002/mrd.20027)

Bhandari RK, Komuro H, Higa M \& Nakamura M 2004b Sex inversion of sexually immature honeycomb grouper (Epinephelus merra) by aromatase inhibitor. Zoological Science 21 305-310. (doi:10.2108/ zsj.21.305)

Bhandari RK, Alam MA, Higa M, Soyano K \& Nakamura M 2005 Evidence that estrogen regulates the sex change of honeycomb grouper (Epinephelus merra), a protogynous hermaphrodite fish. Journal of Experimental Zoology Part A: Comparative Experimental Biology 303 497-503. (doi:10.1002/jez.a.178)

Bhandari RK, Nakamura M, Kobayashi T \& Nagahama Y 2006 Suppression of steroidogenic enzyme expression during androgeninduced sex reversal in Nile tilapia (Oreochromis niloticus). General and Comparative Endocrinology 145 20-24. (doi:10.1016/j. ygcen.2005.06.014)

Bhatia H \& Kumar A 2016 Does anti-androgen, flutamide cancel out the in vivo effects of the androgen, dihydrotestosterone on sexual development in juvenile Murray rainbow fish (Melanotaenia fluviatilis)? Aquatic Toxicology 170 72-80. (doi:10.1016/j. aquatox.2015.11.010)

Billard R 1982 Attempts to inhibit testicular growth in rainbow trout with antiandrogens (cyproterone, cyproterone acetate, oxymetholone) and busulfan given during the period of spermatogenesis. General and Comparative Endocrinology 48 33-38. (doi:10.1016/00166480(82)90035-1)

Blasco M, Fernandino JI, Guilgur LG, Strüssmann CA, Somoza GM \& Vizziano-Cantonnet D 2010 Molecular characterization of cyp11a1 and cyp11b1 and their gene expression profile in pejerrey (Odontesthes bonariensis) during early gonadal development. Comparative Biochemistry and Physiology A: Molecular and Integrative Physiology 156 110-118. (doi:10.1016/j.cbpa.2010.01.006)

Blasco M, Somoza GM \& Vizziano-Cantonnet D 2013 Presence of 11-ketotestosterone in pre-differentiated male gonads of Odontesthes bonariensis. Fish Physiology and Biochemistry 39 71-74. (doi:10.1007/ s10695-012-9651-z)

Borg B 1994 Androgens in teleost fishes. Comparative Biochemistry and Physiology Part C: Toxicology and Pharmacology 109 219-245. (doi:10.1016/0742-8413(94)00063-G)

Cavaco JE, Bogerd J, Goos H \& Schulz RW 2001 Testosterone inhibits 11-ketotestosterone induced spermatogenesis in African catfish (Clarias gariepinus). Biology of Reproduction 65 1807-1812. (doi:10.1095/biolreprod65.6.1807)

Chang CF \& Yueh WS 1990 Annual cycle of gonad histology and steroid profiles in the juvenile males and adult females of the protandrous black porgy, Acanthopagrus schlegeli. Aquaculture 91 179-196. (doi:10.1016/0044-8486(90)90187-R)
Chang CF, Lee MF \& Chen GR 1994 Estradiol-17 $\beta$ associated with the sex reversal in protandrous black porgy, Acanthopagrus schlegeli. Journal of Experimental Zoology 268 53-58. (doi:10.1002/jez.1402680107)

Chen L, Jiang X, Feng H, Shi H, Sun L, Tao W, Xi Q \& Wang D 2016 Simultaneous exposure to estrogen and androgen resulted in feminization and endocrine disruption. Journal of Endocrinology $\mathbf{2 2 8}$ 205-218. (doi:10.1530/JOE-15-0432)

Cheng YY, Tao WJ, Chen JL, Sun LN, Zhou LY, Song Q \& Wang DS 2015 Genome-wide identification, evolution and expression analysis of nuclear receptor superfamily in Nile tilapia Oreochromis niloticus. Gene 569 141-152. (doi:10.1016/j.gene.2015.05.057)

D'Cotta H, Fostier A, Guiguen Y, Govoroun M \& Baroiller JF 2001 Aromatase plays a key role during normal and temperatureinduced sex differentiation of tilapia Oreochromis niloticus. Molecular Reproduction and Development 59 265-276. (doi:10.1002/mrd.1031)

DeQuattro ZA, Hemming JD \& Barry TP 2015 Effects of androstenedione exposure on fathead minnow (Pimephales promelas) reproduction and embryonic development. Environmental Toxicology and Chemistry $\mathbf{3 4}$ 2549-2554. (doi:10.1002/etc.3092)

Feng R, Fang L, Cheng Y, He X, Jiang W, Dong R, Shi H, Jiang D, Sun L \& Wang D 2015 Retinoic acid homeostasis through aldh1a2 and cyp26a1 mediates meiotic entry in Nile tilapia (Oreochromis niloticus). Scientific Reports 5 10131. (doi:10.1038/srep10131)

Fernandino JI, Hattori RS, Kishii A, Strüssmann CA \& Somoza GM 2012 The cortisol and androgen pathways cross talk in high temperatureinduced masculinization: the 11 $\beta$-hydroxysteroid dehydrogenase as a key enzyme. Endocrinology 153 6003-6011. (doi:10.1210/en.20121517)

Fernandino JI, Hattori RS, Moreno Acosta OD, Strüssmann CA \& Somoza GM 2013 Environmental stress-induced testis differentiation: androgen as a by-product of cortisol inactivation. General and Comparative Endocrinology 192 36-44. (doi:10.1016/j. ygcen.2013.05.024)

Gennotte V, Mélard C, D'Cotta H, Baroiller JF \& Rougeot C 2014 The sensitive period for male-to-female sex reversal begins at the embryonic stage in the Nile tilapia and is associated with the sexual genotype. Molecular Reproduction and Development 81 1146-1158. (doi:10.1002/mrd.22436)

Golan M \& Levavi-Sivan B 2014 Artificial masculinization in tilapia involves androgen receptor activation. General and Comparative Endocrinology 207 50-55. (doi:10.1016/j.ygcen.2014.04.026)

Govoroun M, McMeel OM, Mecherouki H, Smith TJ \& Guiguen Y 2001 $17 \beta$-Estradiol treatment decreases steroidogenic enzyme messenger ribonucleic acid levels in the rainbow trout testis. Endocrinology 142 1841-1848. (doi:10.1210/endo.142.5.8142)

Guiguen Y, Jalabert B, Thouard E \& Fostier A 1993 Changes in plasma and gonadal steroid hormones in relation to the reproductive cycle and the sex inversion process in the protandrous seabass, Lates calcarifer. General and Comparative Endocrinology 92 327-338. (doi:10.1006/gcen.1993.1170)

Guiguen Y, Baroiller JF, Ricordel MJ, Iseki K, Mcmeel OM, Martin SA \& Fostier A 1999 Involvement of estrogens in the process of sex differentiation in two fish species: the rainbow trout (Oncorhynchus mykiss) and a tilapia (Oreochromis niloticus). Molecular Reproduction and Development 54 154-162. (doi:10.1002/(SICI)10982795(199910)54:2<154::AID-MRD7>3.0.CO;2-5)

Guiguen Y, Fostier A, Piferrer F \& Chang CF 2010 Ovarian aromatase and estrogens: a pivotal role for gonadal sex differentiation and sex change in fish. General and Comparative Endocrinology 165 352-366. (doi:10.1016/j.ygcen.2009.03.002)

Hattori RS, Fernandino JI, Kishii A, Kimura H, Kinno T, Oura M, Somoza GM, Yokota M, Strüssmann CA \& Watanabe S 2009 Cortisol-induced masculinization: does thermal stress affect gonadal fate in pejerrey, a teleost fish with temperature-dependent sex determination? PLoS ONE 4 e6548. (doi:10.1371/journal.pone.0006548) http://joe.endocrinology-journals.org

DOI: 10.1530/JOE-16-0551
๑) 2017 Society for Endocrinology Printed in Great Britain 
Ijiri S, Kaneko H, Kobayashi T, Wang DS, Sakai F, Paul-Prasanth B, Nakamura M \& Nagahama Y 2008 Sexual dimorphic expression of genes in gonads during early differentiation of a teleost fish, the Nile tilapia Oreochromis niloticus. Biology of Reproduction 78 333-341. (doi:10.1095/biolreprod.107.064246)

Iwamatsu T, Kobayashi H, Sagegami R \& Shuo T 2006 Testosterone content of developing eggs and sex reversal in the medaka (Oryzias latipes). General and Comparative Endocrinology 145 67-74. (doi:10.1016/j.ygcen.2005.07.003)

Jørgensen A, Nielsen JE, Blomberg Jensen M, Græm N \& Rajpert-De Meyts E 2012 Analysis of meiosis regulators in human gonads: a sexually dimorphic spatio-temporal expression pattern suggests involvement of DMRT1 in meiotic entry. Molecular Human Reproduction 18 523-534. (doi:10.1093/molehr/gas030)

Kashimada K, Svingen T, Feng CW, Pelosi E, Bagheri-Fam S, Harley VR, Schlessinger D, Bowles J \& Koopman P 2011 Antagonistic regulation of Cyp26b1 by transcription factors SOX9/SF1 and FOXL2 during gonadal development in mice. FASEB Journal 25 3561-3569. (doi:10.1096/fj.11-184333)

Kobayashi H \& Iwamatsu T 2005 Sex reversal in the medaka Oryzias latipes by brief exposure of early embryos to estradiol-17beta. Zoological Science 22 1163-1167. (doi:10.2108/zsj.22.1163)

Kobayashi T, Kajiura H, Chang X, Nakamura M \& Nagahama Y 1996 Antibodies against trout 3 $\beta$-hydroxysteroid dehydrogenase: their preparation and immunocytochemical use for fish steroidogenic tissue. Zoological Science 13 909-914. (doi:10.2108/zsj.13.909)

Kobayashi T, Nakamura M, Kajiura-Kobayashi H, Young G \& Nagahama Y 1998 Immunolocalization of steroidogenic enzymes (P450scc, P450c17, P450arom, and 3beta-HSD) in immature and mature testes of rainbow trout (Oncorhynchus mykiss). Cell and Tissue Research 292 573-577. (doi:10.1007/s004410051086)

Kobayashi T, Kajiura-Kobayashi H \& Nagahama Y 2003 Induction of XY sex reversal by estrogen involves altered gene expression in teleost, tilapia. Cytogenetic and Genome Research 101 289-294. (doi:10.1159/000074351)

Kokokiris L, Fostier A, Athanassopoulou F, Petridis D \& Kentouri M 2006 Gonadal changes and blood sex steroids levels during natural sex inversion in the protogynous Mediterranean red porgy, Pagrus pagrus (Teleostei: Sparidae). General and Comparative Endocrinology 149 42-48. (doi:10.1016/j.ygcen.2006.05.002)

Kwon JY, Haghpanah V, Kogson-Hurtado LM, McAndrew BJ \& Penman DJ 2000 Masculinization of genetic female Nile tilapia (Oreochromis niloticus) by dietary administration of an aromatase inhibitor during sexual differentiation. Journal of Experimental Zoology 287 46-53. (doi:10.1002/1097-010X(20000615)287:1<46::AIDJEZ6>3.0.CO;2-X)

Lee YH, Du JL, Yueh WS, Lin BY, Huang JD, Lee CY, Lee MF, Lau EL, Lee FY, Morrey C, et al. 2001 Sex change in the protandrous black porgy, Acanthopagrus schlegeli: a review in gonadal development, estradiol, estrogen receptor, aromatase activity and gonadotropin. Journal of Experimental Zoology 290 715-726. (doi:10.1002/jez.1122)

Lee YH, Yueh WS, Du JL, Sun LT \& Chang CF 2002 Aromatase inhibitors block natural sex change and induce male function in the protandrous black porgy, Acanthopagrus schlegeli Bleeker: possible mechanism of natural sex change. Biology of Reproduction $\mathbf{6 6}$ 1749-1754. (doi:10.1095/biolreprod66.6.1749)

Lee YH, Wu GC, Du JL \& Chang CF 2004 Estradiol-17beta induced a reversible sex change in the fingerlings of protandrous black porgy, Acanthopagrus schlegeli Bleeker: the possible roles of luteinizing hormone in sex change. Biology of Reproduction 71 1270-1278. (doi:10.1095/biolreprod.104.030221)

Lee KH, Yamaguchi A, Rashid H, Kadomura K, Yasumoto S \& Matsuyama M 2009 Estradiol-17beta treatment induces intersexual gonadal development in the pufferfish, Takifugu rubripes. Zoological Science 26 639-645. (doi:10.2108/zsj.26.639)
Marandici A \& Monder C 1993 Inhibition by glycyrrhetinic acid of rat tissue 11 beta-hydroxysteroid dehydrogenase in vivo. Steroids $\mathbf{5 8}$ 153-156. (doi:10.1016/0039-128X(93)90062-R)

Matson CK, Murphy MW, Griswold MD, Yoshida S, Bardwell VJ \& Zarkower D 2010 The mammalian doublesex homolog DMRT1 is a transcriptional gatekeeper that controls the mitosis versus meiosis decision in male germ cells. Developmental Cell 19 612-624. (doi:10.1016/j.devcel.2010.09.010)

Mishra S \& Chaube R 2017 Distribution and localization of $3 \beta$-hydroxysteroid dehydrogenase ( $3 \beta$-HSD) in the brain and its regions of the catfish Heteropneustes fossilis. General and Comparative Endocrinology 241 80-88. (doi:10.1016/j.ygcen.2016.04.031)

Miura T, Yamauchi K, Takahashi H \& Nagahama Y 1991 Hormonal induction of all stages of spermatogenesis in vitro in the male Japanese eel (Anguilla japonica). PNAS 88 5774-5778. (doi:10.1073/ pnas.88.13.5774)

Nagahama Y 2000 Gonadal steroid hormones: major regulators of gonadal sex differentiation and gametogenesis in fish. In Proceedings of the 6th International Symposium on Reproductive Physiology of Fish, pp 211-222. Eds B Norberg, OS Kjesbu, GL Taranger, E Andersson \& SO Stefansson. Bergen, Norway: Institute of Marine Research and University of Bergen.

Nakamura M \& Nagahama Y 1989 Differentiation and development of Leydig cells, and changes of testosterone levels during testicular differentiation in tilapia Oreochromis niloticus. Fish Physiology and Biochemistry 7 211-219. (doi:10.1007/BF00004709)

Nakamura M, Hourigan TF, Yamauchi K, Nagahama Y \& Grau GE 1989 Histological and ultrastructural evidence for the role of gonadal steroid hormones in sex change in the protandrous wrasse, Thalassoma duperrey. Environmental Biology of Fishes 24 117-136. (doi:10.1007/BF00001282)

Nakamura M, Kobayashi T, Chang XT \& Nagahama Y 1998 Gonadal sex differentiation in teleost fish. Journal of Experimental Zoology $\mathbf{2 8 1}$ 362-372. (doi:10.1002/(SICI)1097-010X(19980801)281:5<362::AIDJEZ3>3.0.CO;2-M)

Nakamura M, Bhandari RK \& Higa M 2003 The role estrogens play in sex differentiation and sex changes of fish. Fish Physiology and Biochemistry 1 113-117. (doi:10.1023/B:FISH.0000030495.99487.17)

Nozu R \& Nakamura M 2015 Cortisol administration induces sex change from ovary to testis in the protogynous Wrasse, Halichoeres trimaculatus. Sexual Development 9 118-124. (doi:10.1159/000373902)

Okada G, Maruo K, Funada S \& Nakamura M 2008 Differential display analysis of gene expression in female-to-male sex-reversing gonads of the frog Rana rugosa. General and Comparative Endocrinology 155 623-634. (doi:10.1016/j.ygcen.2007.08.015)

Paul-Prasanth B, Bhandari RK, Kobayashi T, Horiguchi R, Kobayashi Y, Nakamoto M, Shibata Y, Sakai F, Nakamura M \& Nagahama Y 2013 Estrogen oversees the maintenance of the female genetic program in terminally differentiated gonochorists. Scientific Reports 32862. (doi:10.1038/srep02862)

Pérez MR, Fernandino JI, Carriquiriborde P \& Somoza GM 2012 Feminization and altered gonadal gene expression profile by ethinylestradiol exposure to pejerrey, Odontesthes bonariensis, a South American teleost fish. Environmental Toxicology and Chemistry $\mathbf{3 1}$ 941-946. (doi:10.1002/etc.1789)

Phuge SK \& Gramapurohit NP 2014 Sex hormones alter sex ratios in the Indian skipper frog, Euphlyctiscy anophlyctis: Determining sensitive stages for gonadal sex reversal. General and Comparative Endocrinology 220 70-77. (doi:10.1016/j.ygcen.2014.04.030)

Piferrer F, Zanuy S, Carrillo M, Solar II, Devlin RH \& Donaldson EM 1994 Brief treatment with an aromatase inhibitor during sex differentiation causes chromosomally female salmon to develop as normal functional males. Journal of Experimental Zoology 270 255-262. (doi:10.1002/jez.1402700304)

Rigel DF, Fu F, Beil M, Hu CW, Liang G \& Jeng AY 2010 Pharmacodynamic and pharmacokinetic characterization of the 
aldosterone synthase inhibitor FAD286 in two rodent models of hyperaldosteronism: comparison with the 11beta-hydroxylase inhibitor metyrapone. Journal of Pharmacology and Experimental Therapeutics 334 232-243. (doi:10.1124/jpet.110.167148)

Ruksana S, Alam MA, Kobayashi Y \& Nakamura M 2011 Differentiation of steroid-producing cells and folliculogenesis in the developing ovary of the Nile tilapia Oreochromis niloticus. Zoological Science $\mathbf{2 8}$ 845-852. (doi:10.2108/zsj.28.845)

Ruwanpura SM, McLachlan RI \& Meachem SJ 2010 Hormonal regulation of male germ cell development. Journal of Endocrinology 205 117-131. (doi:10.1677/JOE-10-0025)

Schulz RW \& Miura T 2002 Spermatogenesis and its endocrine regulation. Fish Physiology and Biochemistry 1 43-56. (doi:10.102 3/A:1023303427191)

Singh AK 2013 Introduction of modern endocrine techniques for the production of monosex population of fishes. General and Comparative Endocrinology 181 146-155. (doi:10.1016/j.ygcen.2012.08.027)

Strüssmann CA, Takashima F \& Toda K 1996 Sex differentiation and hormonal feminization in pejerrey, Odontesthes bonariensis. Aquaculture 139 31-45. (doi:10.1016/0044-8486(95)01161-7)

Strüssmann CA \& Nakamura M 2002 Morphology, endocrinology, and environmental modulation of gonadal sex differentiation in teleost fishes. Fish Physiology and Biochemistry 26 13-29. (doi:10.1023/A:1023343023556)

Sun LN, Jiang XL, Xie QP, Yuan J, Huang BF, Tao WJ, Zhou LY, Nagahama Y \& Wang DS 2014 Transdifferentiation of differentiated ovary into functional testis by long-term treatment of aromatase inhibitor in Nile tilapia. Endocrinology 155 1476-1488. (doi:10.1210/en.2013-1959)

Suzuki A, Tanaka M, Shibata N \& Nagahama Y 2004 Expression of aromatase mRNA and effects of aromatase inhibitor during ovarian development in the medaka, Oryzias latipes. Journal of Experimental Zoology Part A: Ecological Genetics and Physiology 301 266-273. (doi:10.1002/jez.a.20027)

Takasawa K, Kashimada K, Pelosi E, Takagi M, Morio T, Asahara H, Schlessinger D, Mizutani S \& Koopman P 2014 FOXL2 transcriptionally represses Sf1 expression by antagonizing WT1 during ovarian development in mice. FASEB Journal 28 2020-2028. (doi:10.1096/fj.13-246108)

Takatsu K, Miyaoku K, Roy SR, Murono Y, Sago T, Itagaki H, Nakamura M \& Tokumoto T 2013 Induction of female-to-male sex change in adult zebrafish by aromatase inhibitor treatment. Scientific Reports 33400 . (doi:10.1038/srep03400)

Tao WJ, Yuan J, Zhou LY, Sun LN, Sun YL, Yang SJ, Li MH, Zeng S, Huang BF \& Wang DS 2013 Characterization of gonadal transcriptomes from Nile tilapia (Oreochromis niloticus) reveals differentially expressed genes. PLoS ONE 8 e63604. (doi:10.1371/journal.pone.0063604)

Tayaman MM \& Shelton WL 1978 Inducement of sex reversal in Sarotherodon niloticus (Linneus). Aquaculture 14 349-354. (doi:10.1016/0044-8486(78)90017-0)

Villeneuve DL, Blake LS, Brodin JD, Cavallin JE, Durhan EJ, Jensen KM, Kahl MD, Makynen EA, Martinovic D, Mueller ND, et al. 2008 Effects of a $3 \beta$-hydroxysteroid dehydrogenase inhibitor, trilostane, on the fathead minnow reproductive axis. Toxicological Sciences 104 113-123. (doi:10.1093/toxsci/kfn073)

Vizziano D, Randuineau G, Baron D, Cauty C \& Guiguen Y 2007 Characterization of early molecular sex differentiation in rainbow trout, Oncorhynchus mykiss. Developmental Dynamics 236 2198-2206. (doi:10.1002/dvdy.21212)

Vizziano-Cantonnet D, Baron D, Mahè S, Cauty C, Fostier A \& Guiguen Y 2008 Estrogen treatment up-regulates female genes but does not suppress all early testicular markers during rainbow trout male-tofemale gonadal transdifferentiation. Journal of Molecular Endocrinology 41 277-288. (doi:10.1677/JME-08-0039)

Wang DS, Kobayashi T, Zhou LY, Paul-Prasanth B, Ijiri S, Sakai F, Okubo K, Morohashi K \& Nagahama Y 2007 Foxl2 up-regulates aromatase gene transcription in a female-specific manner by binding to the promoter as well as interacting with ad4 binding protein/steroidogenic factor 1 . Molecular Endocrinology 21 712-725. (doi:10.1210/me.2006-0248)

Watanabe KH, Li Z, Kroll KJ, Villeneuve DL, Garcia-Reyero N, Orlando EF, Sepúlveda MS, Collette TW, Ekman DR, Ankley GT, et al. 2009 A computational model of the hypothalamic-pituitary-gonadal axis in male fathead minnows exposed to 17alpha-ethinylestradiol and 17beta-estradiol. Toxicological Sciences 109 180-192. (doi:10.1093/ toxsci/kfp069)

Wu GC, Tomy S, Nakamura M \& Chang CF 2008 Dual roles of cyp19a1a in gonadal sex differentiation and development in the protandrous black porgy, Acanthopagrus schlegeli. Biology of Reproduction 79 1111-1120. (doi:10.1095/biolreprod.108.069146)

Wu GC, Chiu PC, Lin CJ, Lyu YS, Lan DS \& Chang CF 2012 Testicular dmrt1 is involved in the sexual fate of the ovotestis in the protandrous black porgy. Biology of Reproduction 86 41. (doi:10.1095/ biolreprod.111.095695)

Wu GC, Li HW, Huang CH, Lin HJ, Lin CJ \& Chang CF 2016 The testis is a primary factor that contributes to epigenetic modifications in the ovaries of the protandrous black porgy, Acanthopagrus schlegeli. Biology of Reproduction 94 132. (doi:10.1095/biolreprod.115.137463)

Xie QP, He X, Sui YN, Chen LL, Sun LN \& Wang DS 2016 Haploinsufficiency of SF-1 causes female to male sex reversal in Nile tilapia, Oreochromis niloticus. Endocrinology 157 2500-2514. (doi:10.1210/en.2015-2049)

Xu W, Li YY, Lou QQ, Chen XR, Qin ZF \& Wie WJ 2015 Low concentrations of dihydrotestosterone induce female-to-male sex reversal in the frog Pelophylax nigromaculatus. Environmental Toxicology and Chemistry 34 2370-2377. (doi:10.1002/etc.3072)

Yamamoto T 1953 Artificially induced sex-reversal in genotypic males of the medaka (Oryzias latipes). Journal of Experimental Zoology 123 571-594. (doi:10.1002/jez.1401230309)

Zhang WL, Zhou LY, Senthilkumaran B, Huang BF, Sudhakumari CC, Kobayashi T, Nagahama Y \& Wang DS 2010 Molecular cloning of two isoforms of 11beta-hydroxylase and their expressions in the Nile tilapia, Oreochromis niloticus. General and Comparative Endocrinology 165 34-41. (doi:10.1016/j.ygcen.2009.05.018)

Received in final form 11 January 2017

Accepted 1 February 2017

Accepted Preprint published online 1 February 2017 http://joe.endocrinology-journals.org

DOI: 10.1530/JOE-16-0551
() 2017 Society for Endocrinology Printed in Great Britain
Published by Bioscientifica Ltd 